\title{
Satellite observations of energy-banded ions during large geomagnetic storms: Event studies, statistics, and comparisons to source models
}

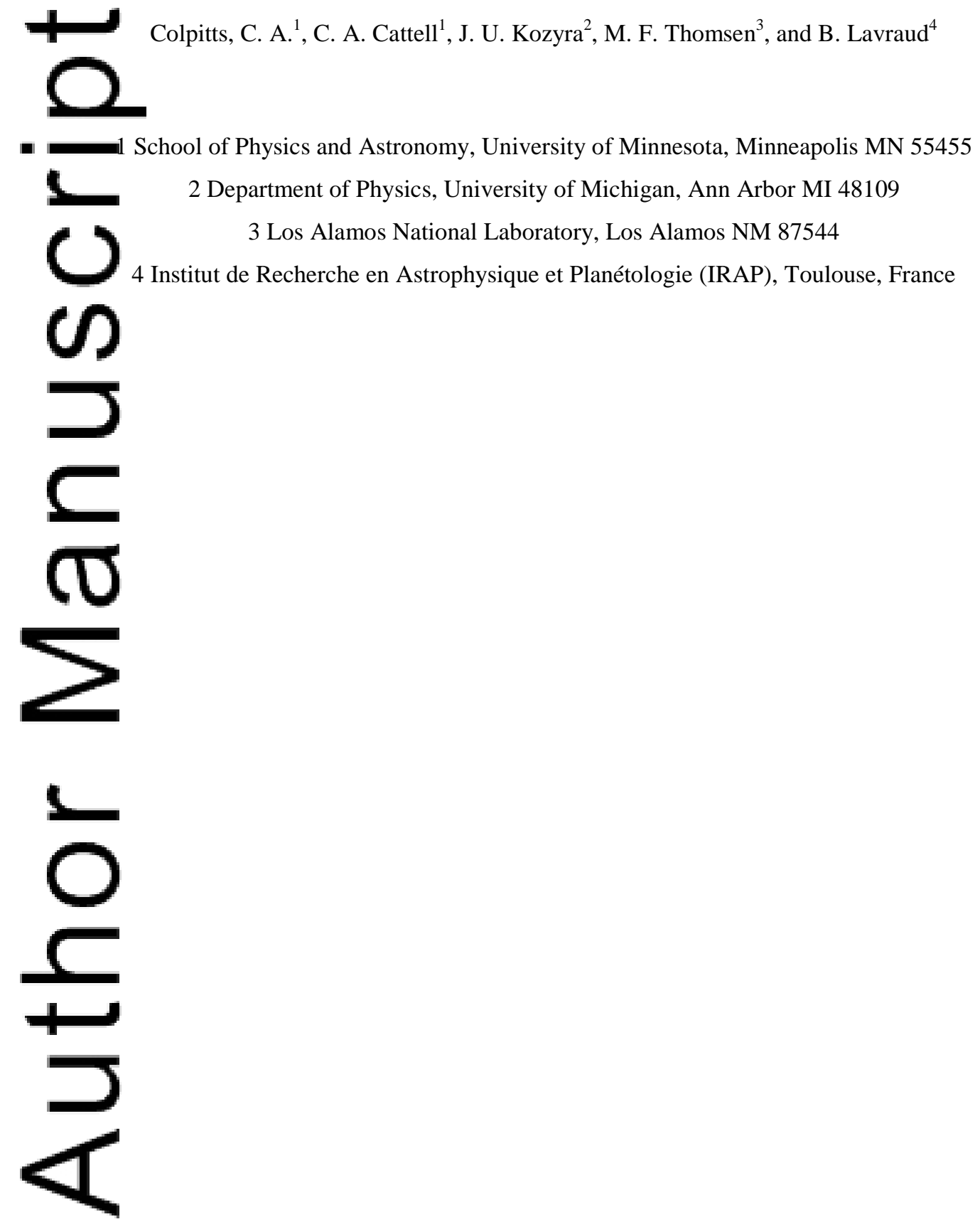

This is the author manuscript accepted for publication and has undergone full peer review but has not been through the copyediting, typesetting, pagination and proofreading process, which may lead to differences between this version and the Version of Record. Please cite this article as doi: 10.1002/2016JA022481

This article is protected by copyright. All rights reserved. 


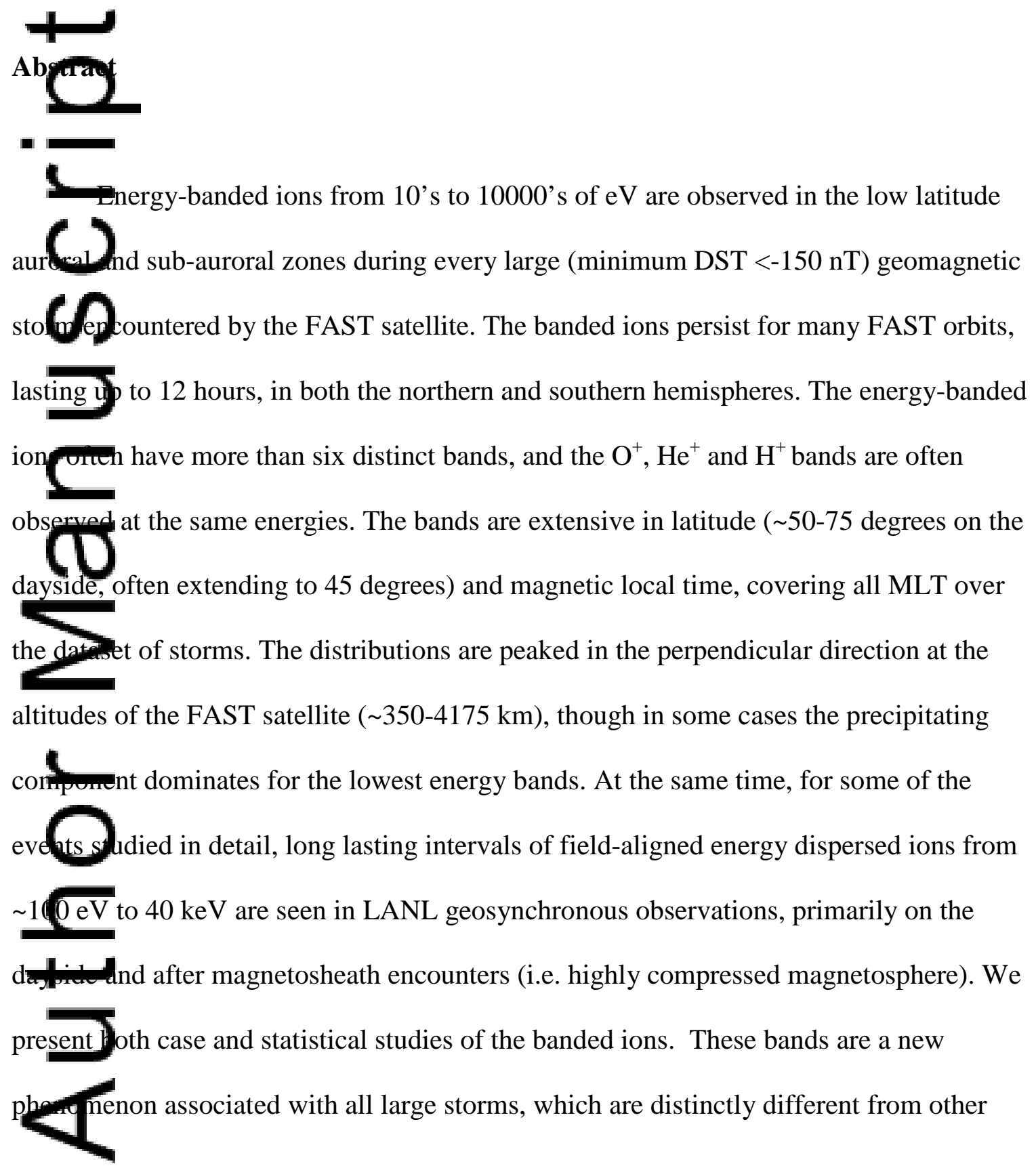


banded populations, and are not readily interpreted using previous models for particle sources, transport and loss. The energy-banded ions are an energetically important component of the inner magnetosphere during the most intense magnetic storms.

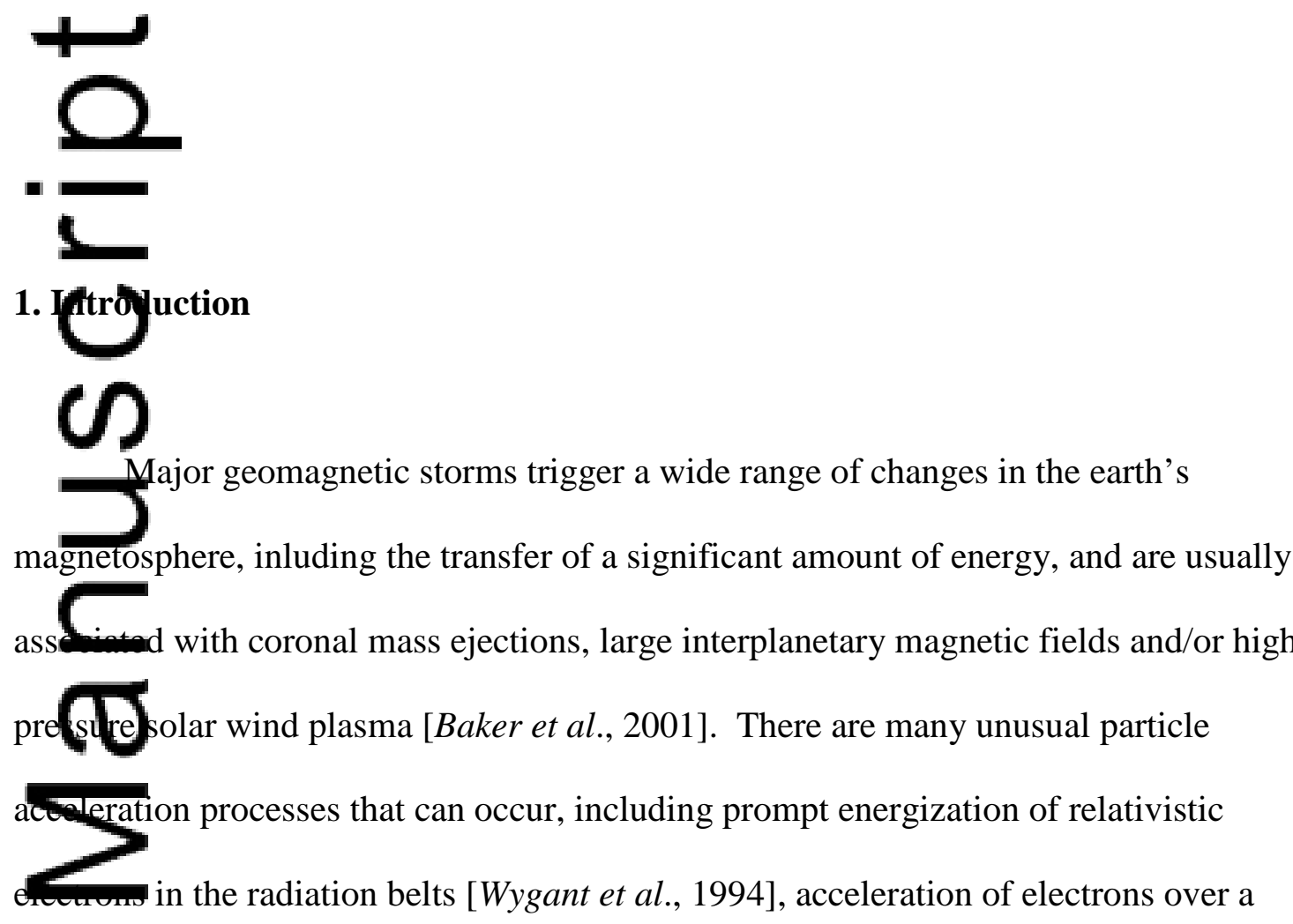

broqd energy range in the auroral zone [Shiokawa et al.,1996; Dombeck et al., 2005;

Nal agma et al., 2007] and strong outflow of ionospheric ions in the polar cap [Moore et al.,1099: Strangeway et al., 2000]. Although much of the research on storms in the auroral zone has focused on electrons, including those that produce sub-auroral red

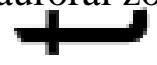

(SADreat red aurora [Kozyra et al., 1993, 1997; Shiokawa et al., 1997], there 
are unusual signatures in the ions that are seen during large storms, and which are sometimes coincident with these electron signatures.

During superstorms (defined as Dst <-240 nT by Mac-Mahon and Gonzalez, [197]), the surprising discovery was made that soft $(<1 \mathrm{keV})$ ions penetrate deep within the 3 asphere - as low as 33 degrees MLAT (L 1.4) [Swider 1990; Huang et al., 2005]. This is much deeper than is possible for ions to drift inward from the magnetotail and emin within this energy range, thus the source of these ions is unknown. FAST obsaryations revealed that these ions often had multiple energy bands [Thomsen et al., 2004. Cattell et al., 2004; Kozyra et al., 2004] ranging from $10 \mathrm{eV}$ to $10 \mathrm{keV}$. As shown in Colpitts et al., [2012] and demonstrated later in this paper, multiple ion species appear in ande energy band, thus this banding cannot be explained by currently known me hini ms which organize bands by constant velocity rather than constant energy seperating ion species into different bands. DMSP observations indicated that the soft iers appeared first without banding and then later developed this feature. However, these obgervations were made at $\sim 850 \mathrm{~km}$ altitude by satellites in the Defense Meteorological Sat ifto Program (DMSP) and thus viewed only the precipitating component. In contrast FAST observations revealed a higher energy component with a double loss cone distribution not seen at DMSP altitudes. The source of these ions and their evolution to $\rightarrow$ multimenergy bands are major focus areas of ongoing research. 
The banded ions are often accompanied by plasma waves banded in frequency [Parrot et al., 2006; Colpitts et al., 2012]. These banded ions are part of a phenomenology of subauroral to midlatitude features, which includes unstructured and structured warm (10s to 10000s of eV) ion distributions (both multiple energy bands and we wesions) with possibly multiple source mechanisms that span three regions during superstorms: (1) the diffuse auroral region, (2) the region between the diffuse aur ra and the plasmasphere and (3) plasmaspheric field lines. Taken together, these featurgprovide clues to the mechanisms that transport warm ions into the inner manetosphere during superstorms. At these times, warm ions can provide up to $30 \%$ of the intense ring current energy in the dawn sector [c.f., Hamilton et al., 1988] making the exergetically important component during extreme events. The deeply perettating warm ions (particularly the protons) transfer considerable energy to the thomal electrons through Coulomb collisions supplying an additional energy source for thumatroral electron temperature peak and SAR arcs and altering the energetics of the subguroral region. A better understanding of the details of this phenomenology and how its (empnts are inter-related is needed to place constraints on source mechanisms and trace_associated effects throughout the geospace system.

In this paper, we focus on warm $(<10 \mathrm{keV})$ ions with multiple energy bands in ord better understand the morphology and evolution of this population. These ions, banded in energy from $10 \mathrm{eV}$ to $10 \mathrm{keV}$, were first reported in conjunction with studies 
of the October, 2003 "Halloween" magnetic storms [Thomsen et al., 2004; Cattell et al., 2004; Kozyra et al., 2004]. The energy-banded ions during the Halloween storms lasted for more than 12 hours, often had more than six distinct bands, and the $\mathrm{O}^{+}$and $\mathrm{H}^{+}$bands were sometimes at the same energies. The bands were evident on both dayside and nig and were extensive in latitude ( $\sim 50-75$ degrees on the dayside, often extending to 45 degrees, the low-latitude limit of the FAST observations). The distributions peaked in the pondicular direction (locally mirroring) at FAST altitudes.

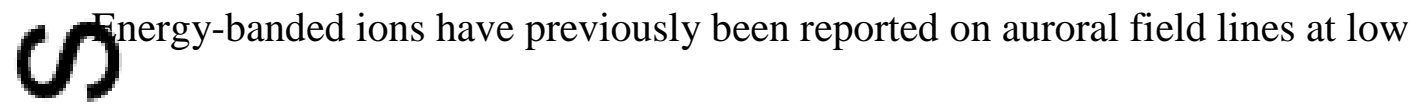
altitudes (FAST, DMSP and DE-2), intermediate altitudes (DE-1) and at high altitudes (Polar and Cluster). In the low altitude auroral zone, energy dispersed discrete bands, wh for a few hours and had equal $\mathrm{O}^{+}$and $\mathrm{H}^{+}$velocities, have been reported du(ndiet times. Two interpretations for the observed structures were proposed (see e.SRehm et al., [1999], Plate 1): (1) convective drift dispersion from an ionospheric heatre ource [Hirahara et al., 1997]; and (2) time-of-flight dispersion from an equatorial acceleration event [Boehm et al., 1999]. Both models predict that $\mathrm{O}^{+}$and $\mathrm{H}^{+}$ ion have the same velocity, that energy bands have ratios dependent on latitude (field line length) and that energy increases with latitude. The equatorial source model assumes an impulsive acceleration process that is broad in latitude, as described by Mauk $+$

[190 Examples include substorm injections and compression of the magnetosphere by high solar wind dynamic pressure. The observed energy dispersion with latitude depends 
on the length of the field line squared and results in bands in energy with ratios of [0.25, $.75,1.25 \ldots]^{2}$. In the ionospheric acceleration model, the latitude dispersion depends on the $\mathbf{E x B}$ drift velocity and results in bands with ratios of $[1,2,3 \ldots]^{2}$ or $[1.5,2.5,3.5 \ldots]^{2}$. Botnm et al. [1999] concluded that both their observations and those of Hirahara et al. [1972 most consistent with the equatorial acceleration mechanism.

A statistical study of $\mathrm{O}+$ and $\mathrm{H}+$ ions using FAST data over the year 2000 also ide rifiog features with multiple-energy bands [Yao et al., 2008]. They concluded that the hydyo and oxygen bands had different source mechanisms because they had different occurrence probabilities and locations. The $\mathrm{H}+$ bands generally were observed at higher latitudes within the auroral oval and during quiet times, whereas the $\mathrm{O}+$ bands occurred at atitudes around the equatorward boundary of the auroral oval during more act 1 in ervals. They concluded that the oxygen bands were consistent with a velocity firtrom higher to lower latitudes and that the bands may supply oxygen from the ienopprere to the ring current during storms. Since $\mathrm{keV}$ protons in an ionospheric plasma (1090-2000 $\mathrm{cm}^{-3}$ with electron temperature of $\left.0.5 \mathrm{eV}\right)$ have a Coulomb loss lifetime of 12 h ars yompared to 0.5-1 day for oxygen [c.f., Kozyra et al., 1987], these bands may initially have been a mixture of the two species with the protons being rapidly depleted by Coulomb collisions leaving the bands dominated by oxygen.

Ysing DE data (at low and mid-altitudes), Frahm et al. [1986] and Winningham et al. [1984] described energy dispersed ion bands, within the region of diffuse aurora, from 
a few $\mathrm{eV}$ to a few $\mathrm{keV}$ and peaked at a pitch angle of $0^{\circ}$. In contrast to the Boehm et al. [1999] and Hirahara et al. [1997] observations, these occurred primarily during the main phase of storms. Similar to Hirahara et al. [1997], the bands were interpreted as being therresurt of convective dispersion from an ionospheric, auroral source.

. 1 higher altitudes, Polar observations of multiple energy dispersed bands $(\sim 1$ 10 (s of keV) were reported by Fennell et al. [1998] and Peterson et al. [1998]. These eve ts hyd $\mathrm{O}^{+}$and $\mathrm{H}^{+}$at the same energy and were weakly peaked at $90^{\circ}$-pitch angle.

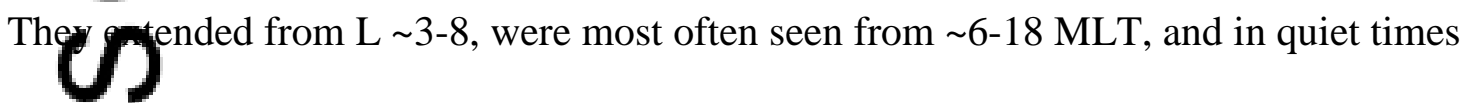
following substorms. Three different explanations were proposed: (1) convection of time variable discrete ion sources in the plasma sheet [Peterson et al., 1998]; (2) time-of-flight foll prompt energization in an electric field pulse associated with substorm dip(1arization with bands dependent on grad B drift time [Li et al., 2000]; and (3) timeVaring $\mathbf{E x B}$ convection of a tail source population for energies $>\sim 1 \mathrm{keV}$ and an i Gmopmeric source for energies < 1 keV [Fennell et al., 1998]. A subsequent particle traging simulation [Ebihara et al., 2004] concluded that the Fennell et al. mechanism was mo emply, with the bands being a result of enhanced convection (during the substorm) followed by reduced convection.

Note that there are other band-like features that have been observed and modeled, inction the ion 'gaps' [see, for example, Kovrazkhin et al., 1999], 'wedge'-type dispersion [Ebihara et al., 2001] and velocity-dispersed ions in the plasma sheet 
boundary layer [Ashour-Abdallah et al., 1992; 2005; Bosqued et al., 1993]. During superstorms, ion distributions resembling wedge-like ions frequently appear as an important component at the lowest latitudes overlapping with the banded ions. These low latuduae warm ion structures have also been described as injections into the low energy tail aring current distribution by McFadden et al., [2001]. These are essentially complementary descriptions of the same phenomena, which is not treated in the present stu $y$. Yany of these previously reported band-like structures are observed during some of the pents with ion banding shown herein and can be co-located with the bands, but are different phenomena; warm energy-banded ions at constant energy across all component species such as these have not previously been reported.

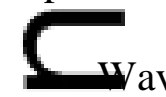
ave emissions with harmonics near the ion cyclotron frequency are also seen durnlarge geomagnetic storms. The occurrence of harmonic emissions in the DEMETER wave data in association with large storms was first described by Parrot et du. [2000]. The fact that energy banded ions were also seen during these intense storms ledColpitts et al. [2012] to investigate the association of the two phenomena, utilizing bot paricle data and wave data from the FAST satellite. Details of the relationships between_the short-lived (in the satellite frame) waves seen on DEMETER and both the banded 1ons and a different type of banded VLF emissions are discussed in Colpitts et al. trater

[2019] The banded waves and ions were observed in all 26 large (minimum Dst $<-100$ 
nT) storms investigated, and it was determined that the waves could be generated by the banded ions, though the exact free energy source was not definitively identified.

There is some evidence to suggest that banded ions are also observed on the same fielutimes as the banded waves reported by Parrot et al. [2006] in the trough region.

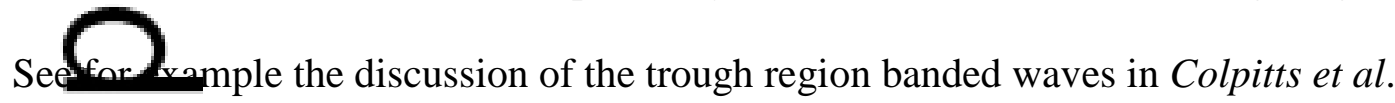
[2012] during the 7-10 November 2004 superstorms at L=2.3 - 3.0 in the DEMETER dat on he nightside in their Figure 2 and the observations of banded ions on these same L valy at this same time but on the dayside in the FAST data in their Figure 1. The same is true on 21 January 2005 for DEMETER at 20:09 UT (9.7 MLT) and FAST at 20:07UT (1.7 MLT) in the northern hemisphere. Since the phenomenon of banded ions covirtually all MLTs and the heating of the thermal plasma by the banded ions cortribues to the subauroral $\mathrm{T}_{\mathrm{e}}$ peak which is also extended over all MLTs, the

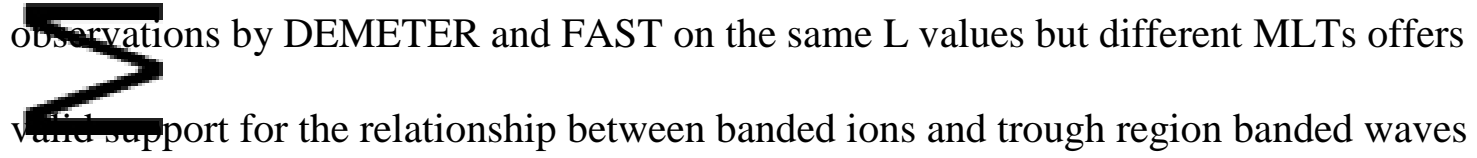
suggesting they are part of the overall phenomenology during superstorms.

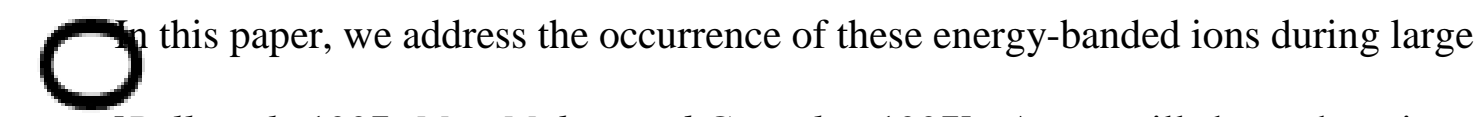
storms_Bell et al., 1997; Mac-Mahon and Gonzalez, 1997]. As we will show, these ions are a distinctly different population from previously reported ion bands and are associated r.

with energization and loss mechanisms will be discussed. The role of this ion population in 
superstorm dynamics will be briefly addressed. The paper will present case studies of three superstorms and one strong storm that provide a range of driver conditions that can be used to illuminate the origin and effects of these ions, as well as statistical data on the ionvoand occurrence. The data sets utilized are described in Section 2. The revealing exandenergy banded ions from the 29-31 October 2003 'Halloween' superstorm is dis ussed in Section 3. The three other exemplary events - 07-11 November 2004, 20-24 No ember 2003 and 26-31 August 1998 - are presented in Section 4. Statistical results on the geurrence of banded ions during the set of eleven superstorms and 26 large stormsare presented in Section 5, and a detailed comparison of the geosynchronous observations with previous models is given in Section 6. Discussion and conclusions are givinection 7.

(v)

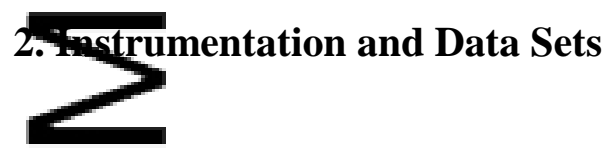

The data presented in this study comes primarily from the FAST satellite, with add (10y data from LANL instruments on geosynchronous satellites provided for the case_studies. The complete features of the FAST particle instrumentation are presented in Carlson et al. [2001] for the electrostatic analyzers (ESAs) and Klumpar et al. [2001] for rasom

the and most of the data presented herein is from these two instruments. The fields 
instruments are described by Ergun et al. [2001] (the electric field and waves instrument) and by Elphic et al. [2001] for the dc and search coil magnetic field instruments. In the initial years of the mission, instruments were turned on and data were usually limited to aunvorantatitudes (>60 ILAT). After 1999, data were regularly obtained at lower latitudes. For four illustrative events shown here, data were obtained down to $45^{\circ}$ inviriant latitude.

Series of 13 geosynchronous satellites carrying the LANL particle instruments wer 19 nched from 1976-2002 into geosynchronous (6.6 $\mathrm{R}_{\mathrm{E}}$, equatorial) orbit with $\sim 10$ second_spin rates. The last 5 of these satellites carried Magnetospheric Plasma Analyzers (MPA) covering electrons and protons $\sim 1 \mathrm{eV}-40 \mathrm{keV}$ [Bame et al., 1993], data from shown here.

D. addition, data from the ACE satellite are used to provide information on solar whenditions. Both magnetic field [Smith et al., 1999] and plasma data [McComas et are used. Dst data were obtained from the WDC for Geomagnetism, Kyoto Dst index service.

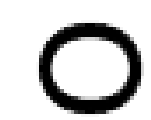

3. The prototype case of the Halloween 2003 storms

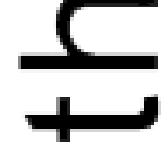

The Halloween storms of October 24 - November 52003 have been studied extensively [see e.g. the AGU Special Collection "Violent Sun-Earth Connection Events 
of October-November 2003, introduction: Gopalswamy, N. et al., 2005], and are among the most severe events of the satellite age. The two storms on October 29-30 and October 30-31 in particular featured Earth-directed CMEs with speeds up to $2200 \mathrm{~km} / \mathrm{s}$, alrowing for a Sun-Earth transit time of just $\sim 19$ hours; and the geomagnetic response wa and intense, with maximum running Ap indices of 252 and 221 for the two stoms, both among the 16 largest values ever recorded. Unfortunately, these storms we so ntense that ACE and WIND solar wind plasma measurements were unavailable due 10 ntamination from the high fluxes of energetic particles, but Skoug et al. [2004] used_Laxwellian fits to the low-resolution data to estimate the solar wind speed, density, and temperature, with estimates of $2240 \mathrm{~km} / \mathrm{s}$ (October 29) and $1710 \mathrm{~km} / \mathrm{s}$ (O) for the maximum flow speeds associated with these two storms. Bigure 1 shows the ACE magnetic field measurements, FAST ion data, and the Dstevel (from the Kyoto World Data Center for Geomagnetism) for the 5-day period frumoerober 28 -November 01 . The two shock fronts are evidenced by the sharp rise in the interplanetary magnetic field ( $\mathrm{B}_{\mathrm{mag}}$, top panel) at 06:00 UT on October 29 and 16:20 UT ongetober 30, which are followed by periods of strong southward $B_{z}$ (fourth panel). After the first shock, there is a $\sim 12$ hour delay before the IMF turns southward, it reaches 25 n1 and remains southward for $\sim 9$ hours, while after the second shock there is a $\sim 3$ $25 \mathrm{ni}$ and houmay, it reaches $30 \mathrm{nT}$, and doesn't turn northward for $\sim 4$ hours. The Kp index (not shown) reaches 9 o at about $~ 20: 00$ UT, indicating the highest level of geomagnetic 
activity. The Dst (bottom panel) shows two very large drops corresponding to the two storms. The fifth panel shows the FAST ion spectrograms, to indicate when in the storm we have FAST ion observations, illustrating the orbital period and several data gaps where there is no ion data for a number of orbits due to data rate and antenna availability. Thenergen in log form from $4-30000 \mathrm{eV}$ on and the color scale is log of energy flu. At this time resolution there is no way to resolve the energy-banded ions (or any oth fegture - the data are merely presented here to show when FAST ion data are avaida), but the orbits in which we observe ion bands are indicated by the magenta bands at the top of the panel. The orbits that will be expanded and plotted in subsequent figures are indicated by a black bar above the magenta bar and the label "Figs 2-5". The mands (in this figure as well as Figures 8,11 and 13) include both dayside and nigtad observations of banded ions (both for most orbits), as there is no correlation beenen phase of storm and observation of bands in the dayside, nightside, or both. Pigure 2 shows 6 consecutive dayside (MLT of $\sim 8$ to 11) auroral passes on 10/31/03 covering the time period 01:54-13:06 UT, but plotted versus latitude rather than UT 7 m left to right, the panels are energy spectrograms of ions with perpendicular (60-120 deg), upgoing (150-180), and downgoing (0-30) pitch angles (these ranges are used for all subsequent pitch angle sorting as well) for the 6 orbits, with energy in log $+1$

form 4-30000 eV on the y-axis, latitude from 45-85 degrees south on the x-axis, and the log of the energy flux in color scale. Several ion bands are visible in the downgoing 
and perpendicular components, at energies from $10 \mathrm{~s}$ of eV to $10 \mathrm{~s}$ of $\mathrm{keV}$, lasting the entire $>11$ hours, over a wide range of latitudes from $~ 50-75$ degrees (more commonly 56-72).

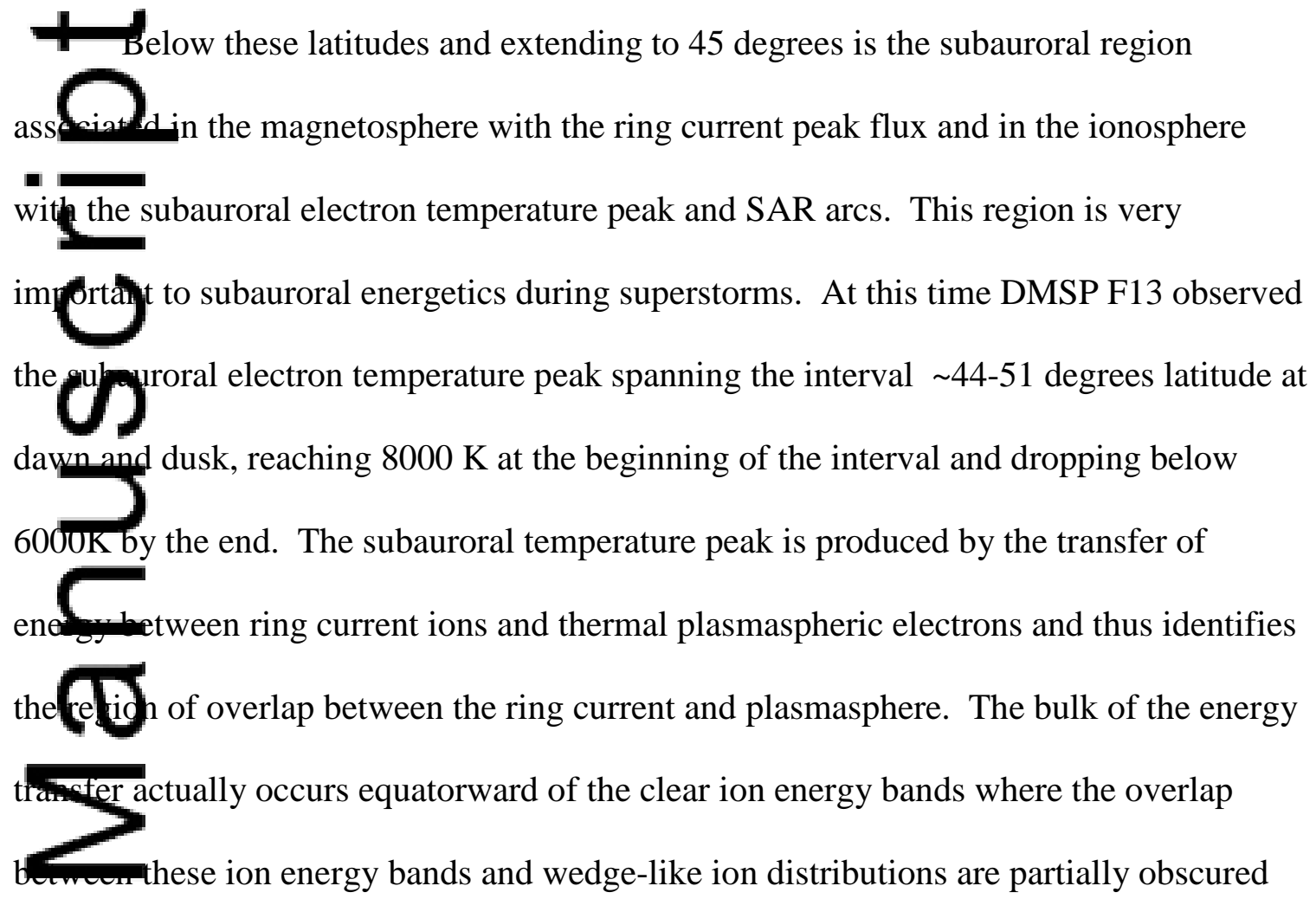
on the FAST spectrograms by penetrating radiation from the high energy ring current and radjatto belts. In other storms in which the penetrating radiation is weaker, wedge-like ion distributions are sometimes observed overlapping with the most equatorward segment of the banded ions.

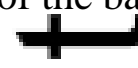

Puring some orbits, there is evidence for local modification of the band energy, possiblydue to local potential drops, e.g. the gradual drop and subsequent rise of the 
energy in the bands at latitude $\sim 67-76$ visible in orbit 28774 . The banded ions are observed primarily equatorward of and within the main auroral zone, although in some passes, they extend to latitudes where the injected cusp ions are observed (e.g. top three passes near $~ 70-75$ degrees). The ion fluxes peak near $90^{\circ}$, with almost no upgoing ions, con close to the satellite altitude and loss to the atmosphere of ions in the loss cone (the few observed upgoing ions in the latter 3 orbits likely mirror below FA T, yhile the majority of the mirroring occurs above the satellite). The lower energy bands particular are evident in the downgoing component, while the higher energy bandsare in some cases restricted to the perpendicular population (e.g. bands at latitudes 56-67 in orbit 28773). Downgoing lower energy ions consistent with the FAST obs precipitating lowest energy bands are seen over the same range of mantid latitudes by DMSP satellites during this storm [Huang et al., 2007], though the peaks of their observations occur during the gaps in the FAST ion data visible in Figure 1. Tmersistent banding was not clear in the DMSP observations.

As mentioned above, cusp ions are also evident at low $(\sim 10-200 \mathrm{eV})$ energies and hig (107 85 ILAT) latitudes in this figure, and the cusp often appears to represent the poleward boundary of the banded ions. This is a common feature in the banded ion observations, though the cutoff is in many cases not very sharp (e.g. orbit 28772, where r.r.

botb-ands and low energy ions are evident at $\sim 67-70 \mathrm{deg}$ ILAT). The question of whether the banded ions are present on open field lines in the cusp is therefore an open 
one, but they are far more common on the closed field lines in the auroral zone and if they are present in the equatorward edge of the cusp they quickly disappear at higher latitudes. Further investigation of the poleward boundary of the banded ions and their presence (or lack thereof) on open field lines could provide information as to their gen andistinechanism, and will be a part of the more rigorous planned statistical study diseussed in Section 7.

Txamples of the different relationships that are observed between down-going elegtrg and the banded ions are shown in Figure 3, which plots the perpendicular ions (left side) and downgoing electrons (right side) for the same passes as Figure 2. Inverted$\mathrm{V}$ electron signatures are evident in the top 5 panels, e.g. in the second panel at $\sim 75-76$, 79 - In all panels (particularly the top panel at $\sim 73-67^{\circ}$, the second at $\sim 76-77$ and the hid panel at $\sim 70-74^{\circ}$ ), broadband electrons up to $\sim 1 \mathrm{keV}$ can be seen. In addition to the ronding, which is equatorward of these electron features, there was strong perpendicular ion heating and ion outflow at energies $<\sim 100 \mathrm{eV}$ at the same latitudes as the observed electrons, in the cusp and auroral zone in association with both 'inverted-V' anc roadband electron acceleration. Note that FAST observed very intense ion outflow $\left(\right.$ of $\mathrm{H}^{+}$and $\mathrm{O}^{+}$), peaking at $>10^{10}$ ions $/ \mathrm{cm}^{2} \mathrm{~s}$ throughout this interval, consistent with previous observations of ionospheric outflow during large geomagnetic storms [Moore et al., T997. The outflow may provide a source population for bands observed at later times. 
The banding seen on the nightside is often more complex and intermittent than on the dayside, as can be seen in Figure 4 which shows energy spectrograms of the perpendicular component of ions (left panels) and the downgoing component of electrons (rignt panel) observed on the nightside during 6 orbits within the same storm. The orbits sho those immediately after the 6 orbits of dayside ions shown in Figure 2, as the nightside bands are less evident during the timespan shown in that figure. During this parfcufy storm, the nightside bands were more prevalent during the recovery phase, thopg previously mentioned there is no consistent correlation between storm phase and_avside/nightside observations. As with the dayside ions, ion bands across the energy range from $10 \mathrm{~s}$ of $\mathrm{eV}$ to $10 \mathrm{~s}$ of $\mathrm{keV}$ are visible and persistent through the 6 orbits ( $\sim$ hars.); but in this case the bands exhibit energy dispersion, with higher energies obsered at higher latitudes, and the ion bands only rarely occur at latitudes above $\sim 65^{\circ}$. However, as on the dayside, the bands are equatorward of the primary auroral electron acereration, evident in the right panels as large-scale inverted-V electron signatures e.g. in the third panel at $\sim 74$ and $72-21^{\circ}$, and occasionally as broadband electron acceleration (bor zon the cusp region (not shown). Intense ion outflow was less common on the nightside, but was observed during orbit 28780. Of course, ion outflow peaks near the polarcap boundary, and the electron spectrograms in the right panels indicate that data 
was not taken in this region for several of these orbits (orbits 28797-28799, data gaps above $\sim 75$ deg.)

Figure 5 shows the energy spectrograms of all ions, $\mathrm{H}+, \mathrm{O}+$, and $\mathrm{He}+$ for the first orroit snown in Figure 2, from 1:56 - 2:13 UT ( 50-80 ILAT). The bands are evident in all 1 omponent species, and although the relative flux varies from peak to peak, the bards are often observed at the same energy in different species; as is the case here with e.g the $100 \mathrm{eV}$ and $~ 1000 \mathrm{eV}$ bands evident in both $\mathrm{H}+$ and $\mathrm{O}+$ (and to a lesser extent, He-1) 2:00-2:09. Therefore, the banding can not be time-of-flight, velocity dispersion from a common source, as proposed by Boehm et al. [1999] and Hirahara et al. [1997] for their quiet time banding events. In addition, there is very little energy dis wion with latitude. There is no evidence for the energy band ratios predicted by eith er of the time-of flight mechanisms discussed by Boehm et al. [1999].

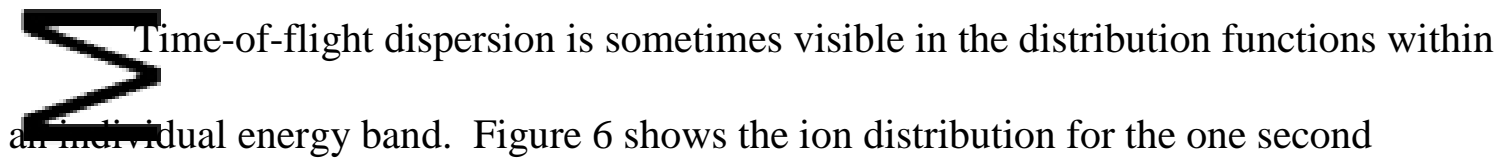
snapshot at 2:03:29-02:03:30 in two different formats: energy flux as a function of energy wit pry angle in color scale (top panel) and energy flux as a function of pitch angle with energy in color scale (bottom panel). There is dispersion evident in the relation between the pitch angles and the energy of particles within a given band at a given time. Fon clear pitch angle dispersion, with the lower energy components (left section of the peak) 
having higher pitch angles $\left(\sim 123-134^{\circ}\right.$, red and orange) and the higher energy

components closer to perpendicular $\left(\sim 72-95^{\circ}\right.$, blue and green $)$.

Figure 7 shows energy spectrograms from the LANL-97A geosynchronous

satellite during the time of the last orbits in Figures 2 and 3, when LANL-97A was on the dayside and in relatively close conjunction with FAST. The banded ions are evident in -

all look directions, but most prominently in the field-aligned directions ( $\mathrm{N}$ and $\mathrm{S}$ ), with cle $\mathrm{r}$ engrgy dispersion. Fits to these dispersion curves do not directly match any of the discron models, as we'll discuss in detail later. Similar energy-dispersed ions are obsith the LANL satellites during most of the strong storms, often following sudden compressions of the magnetosphere. Particle injections in the equatorial plane may provide a source for the banded ions; potential source populations are being addsed in a separate study as discussed in Section 7.

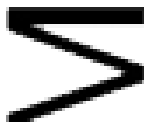

4. Case studies of the November 2004, November 2003 and August 1998 storms $\mathbf{3}$

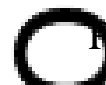

otential plasma sources, as well as energization and loss mechanisms, can be add by comparing the canonical observations obtained during the Halloween storm to gbseryations from other large storms. The next two events occurred during the same seasorry nd of October through end of November), the FAST orbital planes were similar, and sow thern hemisphere data were collected. There were, however, distinct differences 
observed in the time until the convection electric field penetrated to low L-shell, the density of the plasma sheet and the strength of the initial shocks [Mannucci et al, 2008; Abdu et al., 2003].

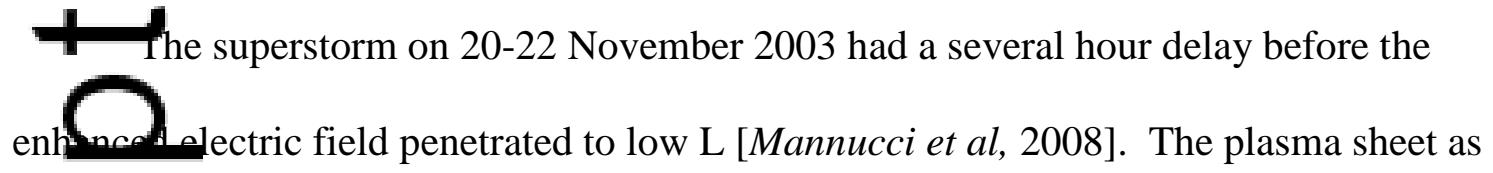

observed by the LANL geosynchronous satellites was dense, reaching $\sim 5 \mathrm{~cm}^{-3}$ at the time of (iningum symH [Ebihara et al., 2005]. In the underlying ionosphere, the subauroral electrgtemperature peak observed by DMSP reached $\sim 10,000 \mathrm{~K}$ but only after the promnt penetration electric field appeared and soft energy-banded ions drifted onto these field lines. In contrast, the November 2004 case had no delay in the electric field pention [Mannucci et al, 2008]. In fact, the largest vertical plasma drifts due to a prontenetration electric field ever recorded over Jicamarca occurred during this event [Fyer al., 2007]. The nightside plasma sheet density observed by the LANL satellites neartimes of minima in symH was only $\sim 1-2 \mathrm{~cm}^{-3}$. The subauroral electron temperature peak was much weaker in this case [Kozyra et al., 2009]. The August 1998 stor ITayo featured a prompt penetration electric field [Abdu et al., 2003], as well as observations of strong ULF waves which are thought to have produced the fast buildup of the electron radiation belts and slow buildup of the inner proton belt that occurred during trats thisudson et al., 2001]. These distinctions between the environments in which the energy-banded ions were produced can offer constraints on potential source 
mechanisms, though it is well beyond the scope of this paper. A study of the much larger set of moderate storms is now underway, and comparing the environmental conditions during those storms, especially those where the bands are not present, to those presented intuis study will hopefully allow us to determine the generation mechanism(s) res? for the ion bands, as discussed in Section 7.

1

A. Novmber 6-11, 2004 ( The November 7-11 2004 storm is shown in Figure 8 in the same format as Figure 1, with the addition of ACE solar wind proton speed, density and temperature to the ACE master data, FAST ion data and Dst. This storm actually consists of two separate sto 1 nd the two shock fronts of the storms are evidenced by sharp rises in $B_{\text {mag }}$ (top parna at 18:00 UT on November 7 and November 9. This is followed by southward Ivir (panel b) which lasts for $~ 12$ hrs after each shock before turning northward (theugh after the second shock hits there is a brief southward period and then a longer nor rwayd period before the true southward turning). These two storms are also evident as largedrops in the Dst index (bottom panel), reaching -370 after the first shock and -290 after the second. This storm interval was associated with solar wind speeds of $\sim 800$ r kmard panel), not nearly as fast as in the Halloween storms but typical of strong geomagnetic storms. The FAST data shows banded ions seen in almost every orbit 
throughout the main and recovery phases of the storm (indicated again by magenta bars above the FAST data, panel f).

Note that the bands are present even at the onset of the storm (first magenta bar), whicn is occasionally but not generally observed. However, the exact time the bands are firs aborned within a given event is somewhat subjective. In this case, as with any time the bands are present at onset, the ions prior to the storm are very weak, structured but not necosarily banded at constant energy in the way the storm-time bands are, present in onlyt the in single loss cone distributions, and confined to a narrow, higher latitude range This is consistent with the quiet time $\mathrm{H}+$ bands observed by Yao et al. [1998]. Only after the onset of the storm (or after the arrival of the penetration electric field if it is as evidenced in the next example) do the bands intensify, expand to include O+ and and extend to lower latitudes. This can happen somewhat gradually, again leating to a bit of subjectivity in determining when the bands "turn on", but the timing of thenthenta bar in this and all figures of this type indicates a time when the ions are clegrly observed to be this new type of storm-time ion bands.

Cigure 9 shows FAST data from 08:48-09:04 UT on November 8, 2004, taken over ILAT from 63.9-47.3 degrees south, MLT 7.3-8.5, and altitude $\sim 3400-3800 \mathrm{~km}$ during the main phase, when Dst was $\sim-320 \mathrm{nT}$ and solar wind speed was $\sim 650 \mathrm{~km} / \mathrm{s}$. $+1$

Not this is the next auroral zone crossing after the interval shown in Figure 1 of Colpitts t al. [2012]. The top four panels plot, respectively, the perpendicular ion energy 
flux from 4-30000 eV, the downgoing ion energy flux, and the ion pitch angle distributions over two different energy ranges, $10-300 \mathrm{eV}$ and 300-10000 eV.

As in previous figures (2,3 and 4), banded ions are prominent in the top two parters and last from 8:50-9:03 UT. They are distinct from the 'wedge'-type dispersion [Elar., 2001] or storm-time ring current ions described by McFadden et al. [2091], which are also evident at the higher energies and lower latitudes. The two differen phenomena can co-occur, as in this event, as well as other days presented herein (seefigre 12). Consistent with the banding events shown above, the ion fluxes peak in the nernendicular direction and there is little or no upgoing flux. The pitch angle distribution can be seen in more detail in the third and fourth panels: there is a double at the higher energies and a single loss cone at lower energies. This pitch angle strut 0 of the ion bands is illustrated more clearly in the left panel of Figure 10, which shows the energy flux distribution of all species of ions at 08:59:17 (indicated by the bratical line in Figure 9). The bands are clearly visible in the ion distribution, inchuding both single loss cone bands at lower energies and double loss cone bands at hig ergergies. The right panel of Figure 10 shows the ion energy flux distribution for $\sim 2 \cdot 03 \cdot 30$ on October 31,2003 , during the Halloween storms and at a time (marked by a verticalblack line in Figure 5) within Figures 2, 3 and 5. In this case there is a clear $+$ singloss cone at lower energies, and at higher energies there is still a single loss cone, but the downgoing flux is considerably less than in the perpendicular direction. 
The bottom two panels of Figure 9 show the energy flux of $\mathrm{H}+$ and $\mathrm{O}+$ ions, using the TEAMS ion mass spectrometer data. Note that the color scales are different in each panel. Ion bands are observed in both species, with several bands visible at the sâne energies in both species, particularly the lower energy bands ( 20-300 eV) as well as $\mathrm{Om}$ higher energy bands. This storm event displays many of the signature features - thatere also clear in the figures showing the warm ions during other storms and des libel above: low energy ions tend to extend to lower latitudes, bands occur for multip orbits (10s of hours), are more prominent on the dawnside, and the existence of oxyon_and hydrogen bands at the same energies is not consistent with previously described mechanisms [Boehm et al., 1999; and Hirahara et al., 1997]. The observation of + and $\mathrm{O}+$ at these low latitudes and with double loss cones at higher energies is als iidntrast to the quiet time observations of Yao et al. [1998], who observed H+ at higher latitudes and with single loss cones only.

\section{B. November 20-22, 2003 Nover} O The November 20-22, 2003 storm differs from the other storms investigated here in that the penetration electric field is delayed by several hours. This feature can potenting offer insight into the formation of the bands. Figure 11 shows an overview of the storm in the same format as Figure 8. The shock front of the storm is evident at 
$\sim 08: 30$ as a sharp rise in $\mathrm{B}_{\text {mag }}$ (top panel), as well as in proton flow speed, density and temperature (panels c-e). A few hours later, $B_{z}$ (second panel) drops below zero (southward IMF), and remains southward for $\sim 12$ hours. The Dst (bottom panel) drops to $-42 \mathrm{ZIT}$, making this the strongest storm of the last solar cycle by this measure, but the sol furidow speed (panel c) only reaches a moderate level of $\sim 780 \mathrm{~km} / \mathrm{s}$.

.

Figure 12 shows perpendicular ion spectra from 12 consecutive dayside (MLT

6-1 passes near the beginning of this storm (onset occurs at 11:22 UT [Mannucci et al. 2097, between the third and fourth panels on the left, orbits 28997 and 28998). The 6 panels_on the left are observed before the penetration electric field is established $(\sim$ 18:00 UT as determined from a combination of TEC, vertical $\mathbf{E} \mathbf{x} \mathbf{B}$ drift, and IEF $E_{y}$ [Maci et al., 2008]), while the panels on the right occur afterward. The bands are alradvident in the first orbit (28995, top left), before the onset of the storm, though thore weak and confined to a narrow latitude range. Around the time when the pemuation electric field arrives (29000, 29001), the bands move to considerably lower latitude ( 50-60 deg as opposed to $\sim 60-70$ both before and after), as do the cusp injectrons visible in orbits 28998-29001. Note that the banded ions are present throughout the interval, both before and after the electric field penetrates. As can be seen in Figure 11 (magenta bars above $6^{\text {th }}$ panel), the banded ions are observed throughout the in rigure main recovery phases of the storm as well. 


\section{August 26-31, 1998}

The geomagnetic storm of August 26-31, 1998 provides another illustrative example of the banded ions, in particular highlighting the presence of the bands at the sandraies in different ion species and the coincidence of the bands with frequencybanded electromagnetic waves. Figure 13 gives an overview of this storm in the same for (at a. Figure 8. The initial shock front is visible in the $\mathrm{B}_{\text {mag }}$ data (top panel) at 7:00 UT Pr ugust 26, and it is followed after $\sim 16$ hours by extended southward IMF $\mathrm{B}_{\mathrm{z}}$ (second panel) lasting $24 \mathrm{hrs}$ with a brief northward turning during that time. The solar wind speed (third panel) drops off quickly over this time, from $\sim 880$ to $\sim 520 \mathrm{~km} / \mathrm{s}$, typalues for storm-time and quiet-time solar wind speed. The Dst (bottom panel) dros $\operatorname{Cr} m \sim 30$ to $\sim-155$, indicating a sizable storm, and FAST banded ions are ousacyed throughout the main and recovery phases of the storm.

Pigure 14 shows FAST data from 05:06-05:11UT (MLT 2.2-2.3, ILAT 70.4-64.1)

on August 30, 1998 (during the recovery phase of the storm in the auroral zone, $\sim 3$ days afte mpeak Dst of $-155 \mathrm{nT}$, with Dst $\sim-50 \mathrm{nT}$ and solar wind speed $\sim 570 \mathrm{~km} / \mathrm{s}$ ), in the same format as Figure 9 but with the flux of $\mathrm{He}+$ ions added in the bottom panel. There is very little flux in the downgoing component (second panel), with only the lowest enemand evident with low flux, perhaps because the lowest energy bands are higher $(>1000 \mathrm{gV})$ than in the case shown in Figure $9(\sim 20 \mathrm{eV})$. This is also evident in the low- 
and high-energy pitch angle plots (third and fourth panel), where the low-energy plot in this case covers 4-2000 eV (high-energy 2000-30000) and the downgoing loss cone is partially filled in at low energies and empty at high energies. As in the case shown in Figure 5 , several energy bands are visible in the $\mathrm{H}^{+}, \mathrm{O}^{+}$, and $\mathrm{He}^{+}$populations at the same ene (in particular 2000 and $\sim 5000 \mathrm{eV}$ from 05:07:15-05:07:45, 1000 and 2000 eV from 05:08:30-05:10:30), ruling out time of flight mechanisms for the generation of the oang.

C. Ctrong VLF emissions with frequencies from $~ 700$ to $2000 \mathrm{~Hz}$ were observed in association with this storm (see Figure 5 in Colpitts et al. [2012], which shows the waves and the ions for the FAST pass just before the one in Figure 9). For this storm, the band aves are not located significantly equatorward of the primary auroral electrons as therer storms, and, in fact, throughout this storm the banded waves and ions are ousecved more in the central auroral region than on the equatorward edge or sub-auroral regrom where they are typically observed. This could be related to the fact that this is not a superstorm; it is the weakest (minimum Dst -155) of the storms shown here and one of the vearer storms in which the banded ions have been observed to date. This can be seen in Table_1, which lists the storms investigated for this study chronologically, as well as the minimum Dst, presence of banded ions ( $Y$ meaning yes for all) and presence of bandwaves (Y again being yes, $\mathrm{P}$ being possible/partial, N/A reflecting the lack of available wave data, green shading representing FAST wave data and yellow shading 
DEMETER data). In fact, the interval shown here is a time of rapidly fluctuating northsouth IMF and recurrent auroral activity. It is most likely a high-speed stream interval following behind the CME that initiated the magnetic storm. The auroral activity generated by the fluctuating IMF prolongs the recovery phase of the storm in Dst. Dhe close connection between the occurrence of waves and of banded ions for streng storms (minimum Dst -150 nT for FAST field data, -100 nT for DEMETER) when wa da a were available on either DEMETER or FAST is presented in Table 1. Unlike the ${ }^{\prime}$ lived ion bands, the banded waves typically persist for only on the order of a few minutes-and are seen during times when the ion density peaks, though there does not appear to be a consistent density threshold that is conditional for the wave observations.

Detan the possible causal connections between the waves and ions are explored in Colgits t al. [2012].
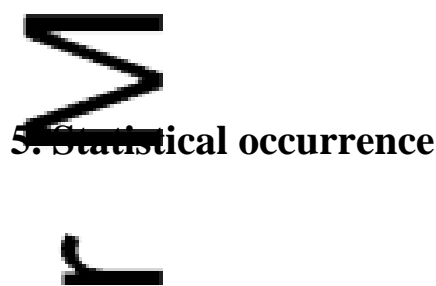

Che warm energy-banded ions were observed in all 24 very large (Dst $<-150 \mathrm{nT}$ ) stormsencountered by the FAST satellite from May 1998 - December 2006 (see Table 1), and an additional 13 large (Dst < -100) storms added to the study to take advantage of the [Colpitts et al., 2012]. A banded ion event was identified when banded ions were 
observed in any region from the auroral zone to deep within the plasmasphere. It was not required that all elements of the complex phenomenology during superstorms including the penetration of ions to extremely low latitudes and the overlap with wedge-type ions decp within the plasmasphere be present for an event to be identified. Thus the statistical stu fouces on banded ions alone and the conditions under which they appear thr ughout the auroral and subauroral regions. Since banded ions are observed during vir ally) all levels of magnetic activity [c.f., Yao et al., 2008] in the diffuse auroral regipn intensity of storms during which they occur is extended to include large and some-moderate storms as well. A more rigorous statistical study incorporating all moderate storms is beyond the scope of this paper, but is planned for the near future and dis in Section 7.

The banded ions were observed in both the northern and southern hemispheres, on the avside and the nightside, though the dayside observations tend to be more constant intrey while on the nightside the bands are more typically dispersed in energy and latikude, with higher energies observed at higher latitudes. The bands occurred throgengut the main and recovery phases of the storms, at all local times MLT 0-24, all FAST alfitudes $\sim 350-4175 \mathrm{~km}$, and geomagnetic latitudes ranging from $45-85$ degrees, extending to the lower latitudes during the main phase and higher latitudes during the recose phase. Due to data rate and contact time with and availability of antennae, we did not always receive data from both the nightside and dayside (and northern and 
southern) portion of an orbit over the desired 45-90 MLAT range, accounting for many of the passes where the bands were not observed, but over the dataset of storms all MLT and latitude are covered. The bands were observed coincident with frequency-banded waves dưrng some intervals of each storm on either FAST or DEMETER in all 27 storms anata exist.

-

The observation of banded warm ions during storms with intensity $<-100 \mathrm{nT}$ is

con (1ste)t with the results of Huang et al., [2005]. They identified significant soft ion pregipation in DMSP observations at subauroral latitudes extending to as low as 33 degreec (but more typically to 40 degrees) during all storms with minimum Dst $<-200 \mathrm{nT}$ (roughly superstorm intensity). In contrast, they found weak warm ion precipitation for stowith minimum Dst in the range -100 to -150 nT but only if the main phase lasted for eet hours. They did not investigate in detail the occurrence of energy bands within this precipitating component.

The typical energy range of the ion bands is $100-10,000 \mathrm{eV}$, but the observed engries extend from $\sim 10-25,000 \mathrm{eV}$. Observed ion densities were typically 1-2 $\mathrm{cm}^{-3}$. 00 extended from $0.5-5.0 \mathrm{~cm}^{-3}$. The bands are typically roughly constant in enerov aside from the occasional nightside dispersion mentioned previously. Bands are often evident in all component species ( $\mathrm{H}+, \mathrm{He}+$, and $\mathrm{O}+)$, and often all at the same eneren with energy flux ratio $\mathrm{O}+/ \mathrm{H}+\sim 0.1-2.0$. The flux peaks in the perpendicular, or trapped opulation, and can have a single loss cone distribution with the bands visible in 
both the downgoing and perpendicular components, or double loss cone distribution with bands only in ions with perpendicular pitch angles. The single loss cone is more common for the lower energy bands, but the distribution is uncorrelated with altitude, latitude, MLL, or storm phase, unlike in previous reports of banded ions such as Yao et al. [2008], whestricted to the year 2000, where a single loss cone distribution was observed for quiet time $\mathrm{H}+$ bands and a double loss cone for storm time $\mathrm{O}+$ bands.<smiles>O</smiles>

6. Tepof models for the origin of the bands using geosynchronous data $\longrightarrow$

During some of the events studied, including the Halloween storms, the LANL geo satellites observed broad regions of energy dispersed field-aligned ions fro $10 \mathrm{eV}$ to $40 \mathrm{keV}$. The ions occurred primarily on the dayside and often in asseciation with strong magnetospheric compressions (inside geosynchronous). The smmrtarteous observation of dispersed banded ions at geosynchronous orbit and the energy banded ions at low altitudes provides the opportunity to test various models for the ouryes of and mechanisms producing the energy-banded ions at low altitudes, as well as the_dispersed ions at geosynchronous. The two sources usually invoked are equatorial (for example, substorm injection on the nightside) and ionospheric (for example, outflow rexamp

fromplar cap boundary). The energy dispersion is interpreted as being due to time- 
of-flight from the source region, in combination with subsequent bounce motion along the magnetic field.

Useful times for the comparison include the bounce period, which for $1 \mathrm{keV} \mathrm{H}^{+}$is 3 Uos and for $1 \mathrm{keV} \mathrm{O}^{+}$is $\sim 1200$ s. Historically, the typical cutoff when modeling and obsurvarticle transport in this region of the magnetosphere is that grad-B dominates forenergies $>100 \mathrm{keV}$ and EXB for energies $<30 \mathrm{keV}$, with some overlap of the two professos in the intermediate 30-100 keV range [Schultz and Lanzerotti, 1974; Sheldon andGsfey, 1993]. McFadden et al. [2001] used FAST data to establish a cutoff at 5-10 keVas the region below which grad-B is not effective at FAST locations. At the energies and L-shells of the FAST observations shown here, there is no doubt that the particles are EX anding eastward, and not grad-B drifting westward, so grad-B and curvature drift eff ct connot be responsible for the observed banding. At the LANL spacecraft location, the-is some grad-B contribution at the highest energies, but as the bands are dispersed downtw $100 \mathrm{eV}$ the grad-B drift cannot explain the dispersion. For L 6-10, only ions with $\mathrm{E}>\sim 1.5 \mathrm{keV}$ will have a large contribution to their motion due to the grad B drift; for lowergergies, co-rotation dominates. The energy dispersion observed by the LANL satellites was compared to that expected from time-of-flight. The relationship between the energy, $\mathrm{E}$, time of observation, $\mathrm{t}$, time of injection, $\mathrm{t}_{0}$, and source distance, $\mathrm{S}$, is given by: 
or defined for $\mathrm{t}$ :

$$
t-t_{0}=S[m / 2 E]^{1 / 2}
$$

For dispersion due to bounce motion along the magnetic field, the source distance depends on multiples of the field-line length and whether the source (observation point) is entine (ionospheric). When both the source and observation points are the same loction, the energy will depend on $n^{2}$ ( $n=1,2,3 \ldots$ bounce number); when they are differenythe energy depends on $[(2 n-1) / 2]^{2}$. Figure 15 shows the time (in minutes after 0209 on 31 October 2003) vs. 1/E $\mathrm{E}^{1 / 2}$ plots for a subset of the LANL 02A ion band observations (thick lines), with linear fits to each band shown underlying the observations. All of the bands observed in both the north- (top panel) and south-looking (bowrmepanel) directions show the expected linear relationship for time-of-flight effects. The of the bands from the linear fits shown in Figure 15, as well as those observed Withernother LANL satellite (97A), are plotted in Figure 16 (along with the calculated envis IIIthe fits) for comparison with the slopes expected for an ionospheric source (S= $1 / 2,21 / 2,51 / 2 \ldots)$ or an equatorial source $(S=1,21,31 \ldots)$, where 1 is the length of the field line (nrgygh the geosynchronous location. The assumed species are $\mathrm{H}^{+}$(top), $\mathrm{He}^{+}$ (middlaland $\mathrm{O}^{+}$(bottom).

A 1 though most of the ion bands fit a time-of-flight dispersion, in some cases it wastorice in ionospheric source and in some for an equatorial source [Thomsen et al., 2004]. Note that, for some bands, multiple bounces are required to fit the dispersion; 
however, not all the intermediate bounces are observed. In addition, multiple source injection times were necessary ( $t_{0}$ in Figure 16). This is not inconsistent with the multiple magnetospheric compressions and/or the FAST observations of ionospheric outflow over a rong interval. The tan shading in Figure 16 indicates some clustering in $\mathrm{t}_{0}$, with most of the times may be separated by roughly the period of ion Pc5 oscillations ( $\sim 3-3.5$ minutes), and 3 vaves are often observed just after the magnetopause compressions in these strog porms. This implies that Pc5 oscillations may play a role in the generation or modulation of these ion bands, but more investigation is required to determine the exact nature of the relationship between the bands and Pc5 waves.

\section{6i(c) ssion and conclusions}

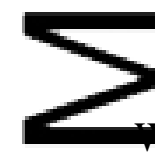

We observe energy-banded ions from $10 \mathrm{~s}$ to $10000 \mathrm{~s}$ of $\mathrm{eV}$ in the auroral and subaurgral zones during every large (minimum Dst $<-150 \mathrm{nT}$, in some cases $<-100 \mathrm{nT}$ ) geonagyetic storm encountered by the FAST satellite. Intense bands with similar properties can persist for 12 hours, as in the Halloween storm. Some degree of ion banding 1 s seen throughout all of the storms, although some individual orbits do not $+1$

dis observed. We observe multiple distinct bands (often > 6), and the $\mathrm{O}^{+}, \mathrm{He}^{+}$and $\mathrm{H}^{+}$bands 
are often observed at the same energies. During the times of banded ion observations, shorter periods of a new type of frequency-banded electromagnetic wave are also observed. In addition, long lasting intervals of field-aligned energy dispersed ions from ruvev to $40 \mathrm{keV}$ are seen in the LANL instruments onboard geosynchronous satellites for $\mathrm{Com}$ the events studied in detail. We find that the geosynchronous ions have enegy dispersion consistent with time-of-flight, but without a consistent source region for 110 the bands, and that the FAST bands only show such dispersion within an indiwigl band and not across bands or latitude. The temporal spacing of the LANL observations appears to be somewhat consistent with the period of Pc5 oscillations. The relationship between this and the energy spacing in the FAST observations is unclear, but it is ascillations play a role in the generation or modulation of the ion bar disvestigation of the potential nature of the role of Pc5 oscillations is beyond the scope of this paper, but will be a part of the statistical study described below. There have been several other independent observations of banded ions and investigations into the source regions and generation mechanisms of the bands; however, non 0 he observations or proposed generation mechanisms can explain the ion bands reported_here. On the basis of the different ILAT and MLT dependence for O+ and $\mathrm{H}+$ energy banded ions in a statistical study of ions observed by FAST, Yao et al. [2008] Ir condurd that the $\mathrm{O}+$ and $\mathrm{H}+$ bands had different source mechanisms. They suggest that the $\mathrm{H}+$ ions are plasma sheet ions generated by impulsive particle injections due to pulsed 
dayside reconnection, while the $\mathrm{O}+$ ions are ionospheric and generated by convective transport. Ebihara et al. [2001] modeled three types of energy banding observed in Viking data referred to as wedge-like structures. The data were consistent with a getreraton mechanism that combined variable source density and location with timedeponvection electric fields. Their 'Type-1' banding is consistent with the en gy dispersion we observe in some cases, in particular in the nightside and occasionally at the low latitude edge of the dayside energy-banded ions, where the ions incra in energy with increasing latitude.

These wedge-like structures cannot be produced by ion drifts alone but require particular spatial or temporal characteristics in the source population [Ebihara et al., Type 1 (ordinary) patterns are produced by a source that is narrow in the radial dirctor and extended in the azimuthal direction described as azimuthal stripes. Smations indicate that the wedge-like ions are formed most likely from a cold ion $>$ sourar $\sim 100 \mathrm{eV}$ ) rather than the hot plasma sheet [Ebihara et al., 2001, 2008]. Yarnauchi et al. [2009] speculate that the cold dense plasma sheet (CDPS) [c.f., Fujimoto et a 97] or superdense plasma sheet intervals [Borovski et al., 1997] are likely sources of the cold plasma for the type 1 wedge-like ion structures. Another possible source 1s the impulsive electric field associated with substorms that is radially confined $+$

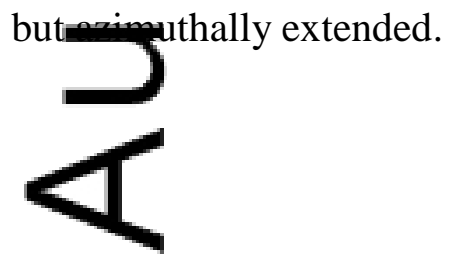


Utilizing a particle tracing code with an idealized storm-time electric field model, Huang et al. [2005, 2007] examined possible source locations for low energy precipitating ions observed by DMSP at low latitudes during major storms. Based on the observed separation between electrons and ions, they concluded that these ions must have a sinside the plasmasphere, not the plasma sheet, and were associated with the large andime-varying penetration electric fields. One of the events discussed was the Hawn storm. The advantage of DMSP is the fact that there are multiple spacecraft witt thability to simultaneously observe precipitating ions, the penetration electric field and the electron temperature peaks; the disadvantage is that the bulk of the energy banded ions shown here are mirroring at higher altitudes and would not be evident in the preting component measured by DMSP.

The comparison of the FAST banded ions and the geosynchronous data during the Haveen storm provides evidence in the FAST data and the LANL data for an ionvopreric source, as well as for a plasma sheet source. The LANL data shows clear evidence for an equatorial dayside source associated with magnetospheric compressions, like boundary layer. The equatorial source observations are consistent with Mauk [1986]and Quinn and McIlwain [1979], as well as with the source characteristics inferred by Boehm et al. [1999]. Although the LANL data are consistent with time-of-flight dis ne the FAST data do not appear to be since the $\mathrm{O}+$ and $\mathrm{H}+$ bands have the same 
energies (not velocities). There is no clear evidence for different sources for the $\mathrm{O}+$ (or $\mathrm{He}+$ ) bands than for the $\mathrm{H}+$ bands.

The banded ions are observed in all of the large storms encountered by the FAST sâtultite, but they are also observed in some more moderate (minimum Dst -100 nT) sto In-particular, the January 212005 storm had a minimum Dst of only -105 nT, but featured several phenomena typically associated with larger storms [Kozyra et al., 2013; 2014], Mcluding warm energy-banded ions similar to those reported herein, with multiple

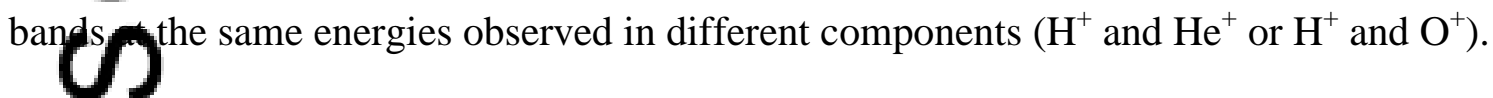
Weare nreparing additional studies of this fascinating storm, including the finding that the observed bands were consistent with time-of-flight mechanisms from a localized sou suppose a superposition of multiple bands formed by protons bouncing bet $\mathrm{ven}$ mirror points combined with the time-of-flight separation of heavier ions $\left(\mathrm{He}^{+}\right.$ ante arriving directly from the source. This type of mechanism would not explain the barmoverved in the case studies shown here, where there are many bands with all three components at the same energies.

Wnother finding from this January 2005 storm is that the bands occurred on the dayside_only during northward IMF conditions, and this together with other plasma characteristics allows us to infer that intermittent capture of low-latitude boundary layer

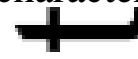

(LIDL here the pands are observed in both northward and southward IMF conditions, this is an 
interesting additional source to be considered for these ions, combined with the ionospheric ion outflow, equatorial plasma, and substorm injections. In addition to the studies of this particular moderate event, we are beginning a study of the much larger subset of moderate storms encountered by FAST as well as quiet times, where we will det ${ }_{\text {in }}$ what percentage of moderate storms the ion bands are observed and if there is athreshold for how strong a storm must be for the bands to be present, or if there is son oner factor besides minimum Dst which determines the presence of the bands. Thig sy will also include statistical studies of the relative strength, number and energy range of the bands in each component species as a function of storm phase, MLT, latitude, altitude, Dst and other parameters as well as address potential source populations for bands, and should give us a clearer picture of how the banded ions are gerertef.
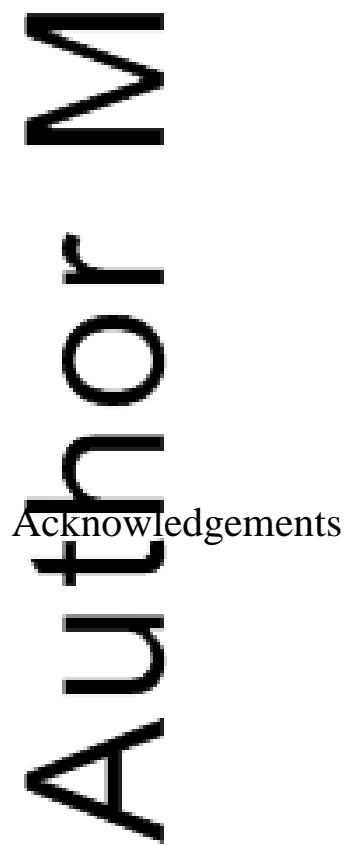
The FAST data used for the figures in this paper is available at http://sprg.ssl.berkeley.edu/fast/scienceprod/welcome.html. The Kyoto Dst data is available at http://wdc.kugi.kyoto-u.ac.jp/dstdir/index.html. The ACE solar wind data is

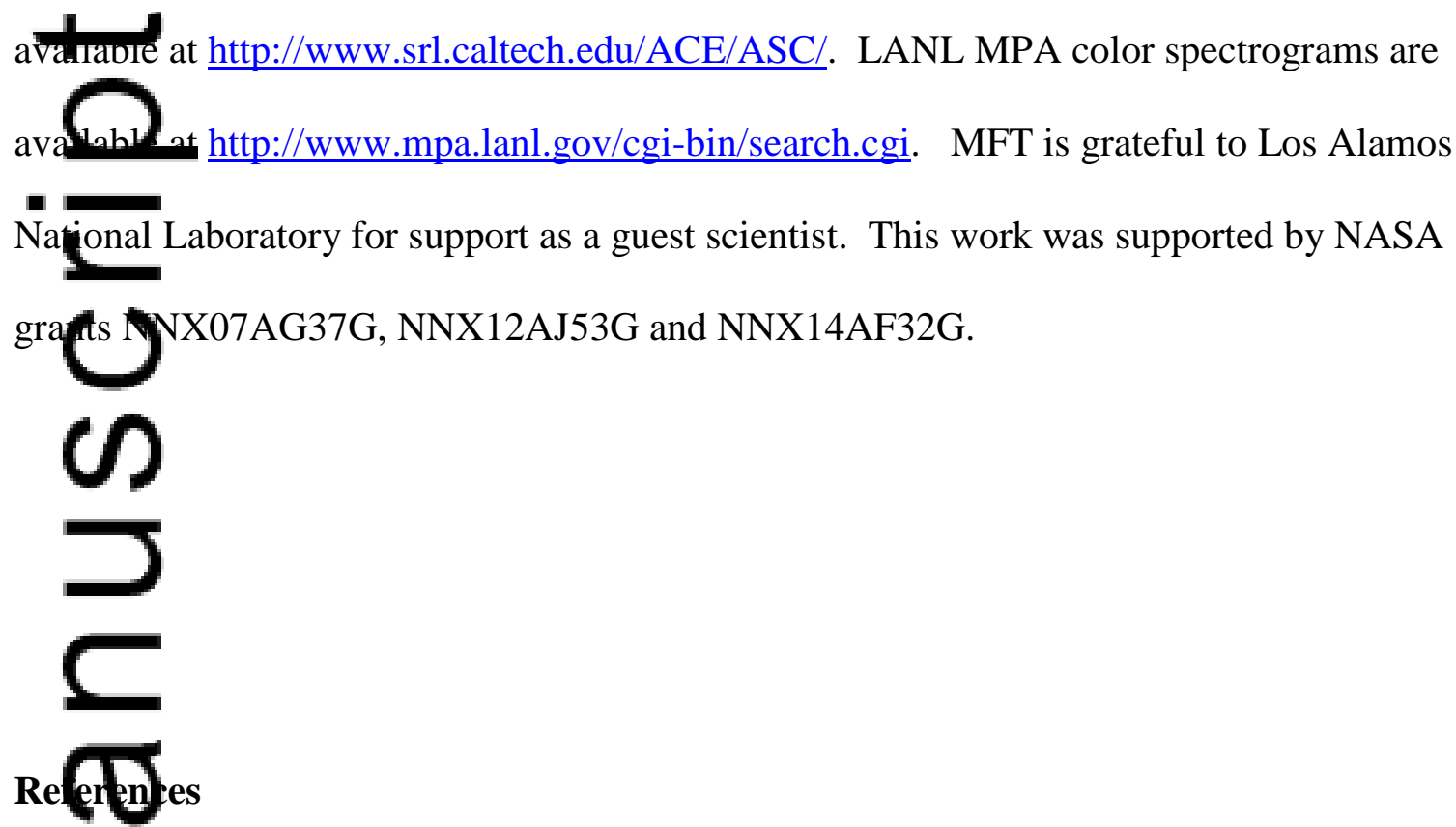
Avd A., C. M. Denardini, J. H. A. Sobral, I. S. Batista, P. Muralikrishna, K. N. Iyer, O. Vel:L, and E. R. Paula (2003), Equatorial electrojet 3-M irregularity dynamics during nragreme disturbances over Brazil: Results from the new VHF radar at São Luís, $J$. Atmos. Sol. Terr. Phys., 65, 1293-1308, doi:10.1016/j.jastp.2003.08.011.

Ashour-Abdalla, M., L. M. Zelenyi, J. M. Bosqued, and R. A. Kovrazhkin (1992), Pre iprtion of fast ion beams from the plasma sheet boundary layer, Geophys. Res. Let 19), 617-620.

As our-Abdalla, M., J. M. Bosqued, M. El-Alaoui, V. Peroomian, L. M. Zelenyi, R. J. Walker, and J. Wright (2005), A stochastic sea: The source of plasma sheet boundary layurion structures observed by Cluster, J. Geophys. Res., 110, A12221, dois0ma29/2005JA011183. 
Baker, D. N., W. Aiello, J. R. Asbridge, R. D. Belian, P. R. Higbie, R. W. Klebesadel, J. G. Laros and E. R. Tech (1985), "Los Alamos Energetic Particle Sensor Systems at Geostationary Orbit," AIAA 85-0243.

Baker, D. N., N. E. Turner, and T. I. Pulkkinen (2001), Energy transport and dissipation in the magnetosphere during geomagnetic storms, Journal of Atmospheric and SolarTêrestrial Physics, Volume 63, Issue 5, p. 421-429.

Baمn, D. J. McComas, M. F. Thomsen, B. L. Barraclough, R. C. Elphic, J. P. Glore_LT. Gosling, J. C. Chavez, E. P. Evans, and F. J. Wymer (1993), Magnetospheric Planma Analyzer for Spacecraft with Constrained Resources, Rev. Sci. Instr., 64, 1026.

Belan, T. D., G. R. Gisler, T. Cayton, and R. Christensen (1992), High-Z Energetic Partal at Geostationary Orbit During the Great Solar Proton Event Series of October 1989, Geophys. Res., 97, 16,897.

Bel___. M. S. Gussenhoven, and E. G. Mullen (1997), Super storms, J. Geophys. Res., 102, 14, 89.

Bo $n$ IIm, M., D. Klumpar, E. Möbius, L. Kistler, J. McFadden, C. Carlson, and R. Ergun, (19)_AST auroral snapshot observations of bouncing ion distributions: Fieldline lengthmeasurements, J. Geophys. Res., 104, 2343.

Borovsky, J. E., M. F. Thomsen, D. J. McComas (1997), The superdense plasma sheet: Prasmaspheric origin, solar wind origin, or ionospheric origin, J. Geophys. Res., 102, 22080

Bosqued, J. M., M. Ashour-Abdalla, M. El Alaoui, V. Peroomian, L. M. Zelenyi, and C. P. Fscoubet (1993), Dispersed ion structures at the poleward edge of the auroral oval: Low-arttude observations and numerical modeling, J. Geophys. Res., 98(A11), 19,181$19,04$.

Carlson_C. W., J. P. McFadden, P. Turin, D. W. Curtis and A. Magoncelli (2001), The Eletron and Ion Plasma Experiment for Fast, Space Sci. Rev., 98, 33-66209.

Caurit. A., M. F. Thomsen, Janet Kozyra, B. Lavraud, J. Borovsky, and J. Dombeck (2014 Energized Banded Ions During Large Geomagnetic Storms: Comparisons of Observa ions at Geosynchronous and Low Altitudes, COSPAR04-A-02925. 
Colpitts, C. A., C. A. A. Cattell, J. U. Kozyra, and M. Parrot (2012), Satellite observations of banded VLF emissions in conjunction with energy-banded ions during very large geomagnetic storms, J. Geophys. Res., doi:10.1029/2011JA017329.

Dombeck, J., C. Cattell, J. R. Wygant, A. Keiling, and J. Scudder (2005), Alfven waves and Poypting flux observed simultaneously by Polar and FAST in the plasma sheet bouncary layer, J. Geophys. Res., 110(A12S90), doi:10.1029/2005JA011269.

Eb dispersion of subkeV ions: Particle simulation and Viking observation, J. Geophys. Res., 10629,571 .

Ebitara, Y. et al. (2004), Multiple Discrete-Energy Ion Features in the Inner Masoshere: Event of February 9,1998, Annales Geophys., 22: 1297-1304.

Eb 6 Y., M.-C. Fok, S. Sazykin, M. F. Thomsen, M. R. Hairston, D. S. Evans, F. J. Rich and M. Ejiri (2005), Ring current and the magnetosphere-ionosphere coupling during the superstorm of 20 November 2003, J. Geophys. Res., 110, A09S22, doi:10.1029/2004JA010924.

Ebimans., Kistler, L. M., and Eliasson, L. (2008), Imaging cold ions in the plasma sheetfrom the Equator-S satellite, Geophys. Res. Lett., 35, L15103, doi(11) 29/2008GL034357.

Erphic, R. C., J. D. Means, R. C. Snare, R. J. Strangeway, L. Kepko, R. E. Ergun (2001), Magnetic field instruments for the Fast Auroral Snapshot Explorer, Space Sci. Rev., 98,

Ergun, R. E., C.W. Carlson, F.S. Mozer, G. T. Delory, M. Temerin, J. P McFadden, D. Pankow, R. Abiad, P. Harvey, R. Wilkes, H. Primsch, R. Elphic, R. Strangeway, R. Pfaff and Cattell (2001), The FAST satellite fields instrument, Space Sci. Rev., 98, 67.

Fejer_B_G., J. W. Jensen, T. Kikuchi, M. A. Abdu, and J. L. Chau (2007), Equatorial Ion spheric Electric Fields During the November 2004 Magnetic Storm, J. Geophys. Res., 112, A10304, doi:10.1029/2007JA012376.

Fendu. F., Chen, M. W., Roeder, J. L., Peterson, W. K., Trattner, K. J., Friedel, R., Livi.S. Grande, M., Perry, C., Fritz, T. A., and Sheldon, R. (1998), Multiple discreteenergy ion features in the inner magnetosphere: Polar observations, Physics of Space Plom as, 15, 395. 
Frahm, R. A., Reiff, P. H., Winningham, J. D. and Burch, J. L. (1986), Banded ion morphology: Main and recovery storm phases, in Ion Acceleration in the Magnetosphere and Ionosphere, Geophys. Monogr. Ser., vol. 38, edited by T. Chang et al., pp. 98-107, AGU, Washington, D. C.

Fuj/moto, M., T. Terasawa, and T. Mukai (1997), The cold-dense plasma sheet: A Gegairy perspective, Space Sci. Rev., 80, 325.

Gopalswamy, N., L. Barbieri, E. W. Cliver, G. Lu, S. P. Plunkett, and R. M. Skoug (2095), Introduction to violent Sun-Earth connection events of October-November 2003, J. Geopnys. Res., 110, A09S00, doi:10.1029/2005JA011268.

Hanilitest

, D. C., G. Gloeckler, F. M. Ipavich, W. Stüdemann, B. Wilken, and G. Kremser (1988 Ring current development during the great geomagnetic storm of February 1986, J. Coplys. Res., 93(A12), 14343-14355, doi:10.1029/JA093iA12p14343.

Harnett, E. M., R. M. Winglee, A. Stickle, and G. Lu (2008), Prompt ionospheric/magnetospheric responses 29 October 2003 Halloween storm: Outflow and ene grzation, J. Geophys. Res., 113, A06209, doi:10.1029/2007JA012810.

Hirphana M., A. Yamazaki, K. Seki, T. Mukai, E. Sagawa, N. Kaya, and H. Hayakawa (197. Tharacteristics of downward flowing ion energy dispersions observed in the lowaltitude central plasma sheet by Akebono and DMSP, J. Geophys. Res., 102(A3), 48214030

Furvarr, I., and B. C. Lovell (2010), Traveling ionospheric disturbances and their relations to storm-enhanced density features and plasma density irregularities in the local evening and nighttime hours of the Halloween superstorms of 29-31 October 2003, J. Geoprys. Res., 115, A09327, doi:10.1029/2009JA015125.

Hußng. Y., W. J. Burke, and C. S. Lin (2005), Ion precipitation in the dawn sector during geomagnetic storms, J. Geophys. Res., 110, A11213, doi:10.1029/2005JA011116.

Huang, C.Y., W.J. Burke, and C.S. Lin (2007), Low-energy ion precipitation during the Haurween storm, J. Atmos. Sol. Terr. Phys., 69, 101-108.

Hudson M.K., S.R. Elkington, J.G. Lyon, M. Wiltberger and M. Lessard (2001), Radiation Belt Electron Acceleration by ULF Wave Drift Resonance: Simulation of 1997 and 98 Storms, Geophysical Monograph Series, Vol. 125, 289-296. 
Klumpar, D. M., E. Möbius, L. M. Kistler, M. Popecki, E. G. Shelley, E. Hertzberg, K. Crocker, M. Granoff, Li Tang, C. W. Carlson, J. McFadden, B. Klecker, F. Eberl, E. Kuenneth, H Kaestle, M. Ertl, W. K. Peterson, and D. Hovestadt (2001), The Time-ofFlight Energy, Angle, Mass Spectrograph (TEAMS) Experiment for FAST, Space Sci. Rev, 98, 197.

Ko razykin, R. A., Sauvaud, J. -A., and Delcourt, D. C. (1999), Interball-Auroral obstans of 0.1-12keV ion gaps in the diffuse auroral zone, Ann. Geophys., 17, 734.

Kogyra, J. U., E. G. Shelley, R. H. Comfort, L. H. Brace, T. E. Cravens, and A. F. Nagy (1987), The role of ring current $\mathrm{O}^{+}$in the formation of stable auroral red arcs, J. Geophys. Re., 92A7), 7487-7502, doi:10.1029/JA092iA07p07487.

Kozyr J.U., M. O. Chandler, D. C. Hamilton, W. K. Peterson, D. M. Klumpar, D. W. Slale, J. Buonsanto, and H. C. Carlson (1993), The role of ring current nose events in producing SAR arc intensifications during the main phase: Observations during the September 19-24, 1984 Equinox Transition Study (ETS), J. Geophys. Res., 98, 9267-83.

Ko yra, J. U., A. F. Nagy, D. W. Slater, The high altitude energy source for stable auroral red-1 arcs (1997), (Invited Review), Reviews of Geophysics, 35, 2, pg., 155-190.

Ko ya. U., B. J. Anderson, P. C. Brandt, C. A. Cattell, J. P. Dombeck, M. R. Hairston, R. A. Heelis, C. Y. Huang, H. Korth, M. W. Liemohn, M. J. Mendillo, D. G. Mitchell, L. J. Raxton, C. J. Pollock, A. J. Ridley, K. Shiokawa, M. F. Thomsen, L. J. Zanetti (2004), Coupling processes in the inner magnetosphere associated with midlatitude red auroras durng superstorms, Eos Trans. AGU, 85(47), Fall Meet. Suppl., SM12B-03 INVITED.

Kozyra, J. U., W. B. Manchester IV, C. P. Escoubet, S. T. Lepri, M. W. Liemohn, W. D. Gotrzarez, M. W. Thomsen, and B. T. Tsurutani (2013), Earth's collision with a solar filayemy 21 January 2005: Overview, J. Geophys. Res. Space Physics, 118, doi.10.1002/jgra.50567.

Ko yra, J. U., M. W. Liemohn, C. Cattell, D. DeZeeuw, C. P. Escoubet, D. S. Evans, X. Fang, M.-C. Fok, H. U. Frey, W.D. Gonzalez, M. Hairston, R. Heelis, G. Lu, W.B. Mantinster IV, S. Mende, L. J. Paxton, L. Rastaetter, A. Ridley, M. Sandanger, F. Sor Sotirelis, M. W. Thomsen, B. T. Tsurutani, O. Verkhoglyadova (2014), Solar filament impact on 21 January 2005: Geospace consequences, J. Geophys. Res. Space Physics,119, doi:10.1002/2013JA019748. 
Li, X., Baker, D. N., Temerin, M., Peterson, W. K., and Fennell, J. F. (2000), Multiple discrete-energy ion features in the inner magnetosphere: Observations and Simulations, J. Geophys. Res., 27, 1447.

Mac-Mahon, R. M., and W. D. Gonzalez (1997), Energetics during the main phase of geomagnetic superstorms, J. Geophys. Res., 102(A7), 14199-14207, dô.10.1029/97JA01151.

Ma. J., B. T. Tsurutani, M. A. Abdu, W. D. Gonzalez, A. Komjathy, E. Echer, R. A_iiima, G. Crowley, and D. Anderson (2008), Superposed epoch analysis of the dayside ionospheric response to four intense geomagnetic storms, J. Geophys. Res., 113, A0OAVZ, doi:10.1029/2007JA012732.

${ }^{2}(2)$

H. (1986), Quantitative modeling of the 'convection surge' mechanism of ion accolegion, J. Geophys. Res., 91, 13,423.

Mc Comas, D. J., S. J. Bame, P. Parker, W. C. Feldman, J. L. Phillips, P. Riley and J. W. Griffey 1999), Solar Wind Electron Proton Alpha Monitor (SWEPAM) for the Advanced Composition Explorer, Space Sci. Rev., 86, 563, doi (O.T23/A:1005040232597.

McFadden, J. P., Y. K. Tung, C. W. Carlson, R. J. Strangeway, E. Moebius, and L. M. Ki le01), FAST observations of ion outflow associated with magnetic storms, in Space Weather, Geophys. Monogr. Ser., vol. 125, edited by P. Song, H. J. Singer, and G. L. Stscoe, pp. 413-421, doi:10.1029/GM125p0413, AGU, Washington, D. C.

Movr, T. E., W. K. Peterson, C. T. Russell, M. O. Chandler, M. R. Collier, H. L. Collin, P. D. Craven, R. Fitzenreiter, B. L. Giles, and C. J. Pollock (1999), Ionospheric mass ejection in response to a CME, Geophys. Res. Lett., 26, 2339.

Nal amma, A., K. Shiokawa, K. Seki, R. J. Strangeway, J. P. McFadden, and C. W. Carson 2007), Particle and field characteristics of broadband electrons observed by the FAST satellite during a geomagnetic storm, J. Geophys. Res., 112, A06220, doi(10.1029/2006JA012184.

Patur, M., A. Buzzi, O. Santolík, J. J. Berthelier, J. A. Sauvaud, and J. P. Lebreton (2006) New observations of electromagnetic harmonic ELF emissions in the ionosphere by the DEMETER satellite during large magnetic storms, J. Geophys. Res., 111, A08301, doi:10.1029/2005JA011583. 
Peterson, W. K., Trattner, K. J., Lennartsson, O. W., Collin, H. L., Baker, D. N., Pulkkinen, T. I., Toivanen, P. K., Fritz, T. A., Fennell, J. F., and Roeder, J. L. (1998), Imaging the plasma sheet with energetic ions from the Polar satellite, Proc. of ICS-4, Terra Sci. Publishing, Tokyo, 813.

Quinn, J M., and McIlwain, C. E. (1979), Bouncing ion clusters in the Earth's magnetosphere, J. Geophys. Res., 84, 7365.

Sch Land L. J. Lanzerotti (1974), Particle Diffusion in the Radiation Belts. Sprinoer_Verlag, New York.

1

Sheraom, R. B. and J. D. Gaffey, Jr (1993), Particle tracing in the magnetosphere: New alg rithins and results. Geophys. Res. Lett., 20, 767--770.

Shipk ma, K., K. Yumoto, C.-I. Meng, and G. Reeves (1996), Broadband electrons obser by the DMSP satellites during storm-time substorms, Geophys. Res. Lett., $23(18) 2529-2532$.

Shiokawa, K., C.-I. Meng, G. D. Reeves, F. J. Rich, and K. Yumoto (1997), A multievent stu yorbroadband electrons observed by the DMSP satellites and their relation to red aur berved at midlatitude stations, J. Geophys. Res., 102(A7), 14,237 - 14,253.

Smth W. W., J. L'Heureux, N. F. Ness, M. H. Acuna, L. F. Burlaga, and J. Scheifele (1999), The ACE Magnetic Fields Experiment, Space Sci. Rev., 86, 613, doi: 10:T023/A:1005092216668.

Srargeway, R. J., C. T. Russell, C. W. Carlson, J. P. McFadden, R. E. Ergun, M. Temerin, D. M. Klumpar, W. K. Peterson, and T. E. Moore (2000), Cusp field-aligned curcents and ion outflows, J. Geophys. Res., 105, 21,129.

Swjer, W. (1990), Precipitating and trapped ions and electrons observed at $840 \mathrm{~km}$ durngty e Great Magnetic Storm of February 1986, J. Geophys. Res., 95(A7), 1041710425_doi:10.1029/JA095iA07p10417.

Thomsen, M. et al. (2004), Energized Ions in the Dayside Magnetosphere During the SElevents of Late October 2003, EOS Trans. AGU, SH42A-05, AGU Spring 2004.

Winning ham, J. D., Burch, J. L., and Frahm (1984), R. A., Bands of ions and angular V's: A conjugate manifestation of ionospheric ion acceleration, J. Geophys. Res., 89, 1749. 
Wu, C.-C., et al. (2005), Flare-generated shock evolution and geomagnetic storms during the "Halloween 2003 epoch": 29 October to 2 November, J. Geophys. Res., 110, A09S17, doi:10.1029/2005JA011011.

Wygant, J., F. et al. (1994), Large amplitude electric and magnetic field signatures in the inner magnetosphere during injection of $15 \mathrm{MeV}$ electron drift echoes, Geophys. Res. Lê. 21, 1739.

Xia-G. Zong, and L. Chen (2009), Pitch-angle distribution evolution of energetic electrons in the inner radiation belt and slot region during the 2003 Halloween storm, $J$. Gephys. Res., 114, A01215, doi:10.1029/2008JA013068.

Ya tauopi, M., Y. Ebihara, I. Dandouras, and H. Reme (2009), Dual source populations of stbetrm-associated ring current ions, Ann. Geophys., 27, 1431-1438.

Ya K. Seki, Y. Miyoshi, J. P. McFadden, E. J. Lund, and C. W. Carlson (2008), Statistical properties of the multiple ion band structures observed by the FAST satellite, J. Geopys. Res., 113, A07204, doi:10.1029/2008JA013178.

\section{Figare Captions:}

Figun 1. ACE magnetic field measurements of (a) magnitude of B ( $\left.\mathrm{B}_{\mathrm{mag}}\right)$; (b) GSM $\mathrm{B}_{\mathrm{x}}$;

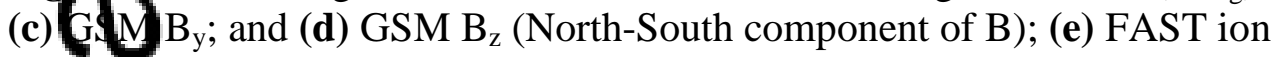
spectrograms, showing all times when FAST ion data was taken during the storm (ntwgenta bars above this panel represent orbits in which banded ions are observed, black bar and Figs 2-5" indicate the orbits which will be shown expanded in subsequent frours, and (f) Dst level (from the Kyoto World Data Center for Geomagnetism) for the 5-day period from October 28-November 01, 2003.

Figurcz. FAST energy spectrograms of ions with (a) perpendicular (60-120 deg), (b) upg ints (150-180), and (c) downgoing (0-30) pitch angles for 6 consecutive dayside (M.T_ 8 to 11) auroral passes on 10/31/03 covering the time period 01:54-13:06 UT, with-energy in log form from 4-30000 eV on the y-axis, latitude from 45-85 degrees sou h on the x-axis, and the log of the energy flux in color scale.

Fyymes, (a) Perpendicular ions and (b) downgoing electrons for the same passes and in the format as Figure 2. 
Figure 4. Energy spectrograms of (a) the perpendicular component of ions and (b) the downgoing component of electrons observed on the nightside (MLT 15-22) during the 6 orbits immediately after the 6 orbits of dayside ions shown in Figure 2.

Figure 5. Energy spectrograms of (a) all ions, (b) $\mathrm{H}+$, (c) $\mathrm{O}+$, and (d) $\mathrm{He}+$ for the first orbjt shown in Figure 2, from 1:56 - 2:13 UT ( 50-80 ILAT). The bands are evident in alror the component species, and often at the same energy in different species (e.g. the $\sim 10$ er and $\sim 1000 \mathrm{eV}$ bands evident in both $\mathrm{H}+$ and $\mathrm{O}+$ and to a lesser extent, $\mathrm{He}+$ fro 2:09) and therefore cannot be time-of-flight, velocity dispersion from a cømmon source. Black vertical line indicates time of data shown in Figure 10.

Figure . Ion distribution for the one second snapshot at 2:03:29-02:03:30 in two differen formats: (a) energy flux as a function of energy with pitch angle in color scale, and nergy flux as a function of pitch angle with energy in color scale. The bands at $\sim 20 \mathrm{nd} \sim 100 \mathrm{eV}$ visible as peaks in the top panel have clear pitch angle dispersion, wit helower energy components (left section of the peak) having higher pitch angles $\left(\sim 123-134^{\circ}\right.$, red and orange) and the higher energy components closer to perpendicular $(\sim 72-95)$, blue and green).

Fig are 7. Energy spectrograms from the LANL-97A geosynchronous satellite during the time last orbits in Figures 2 and 3, when LANL-97A was on the dayside and in rela close conjunction with FAST. The banded ions are evident in all look dirct ods, but most prominently in the field-aligned directions (N and $\mathrm{S}$ ), with clear eneroy dispersion.

Figne 8. ACE magnetic field measurements of (a) magnitude of B ( $\left.\mathrm{B}_{\mathrm{mag}}\right)$, and (b) Nortursouth component of $\mathrm{B}\left(\mathrm{B}_{\mathrm{z}}\right)$; (c) solar wind proton speed, (d) temperature and (e) density; (f) FAST ion spectrograms, showing all times when FAST ion data was taken during the storm (magenta bars above this panel represent orbits in which banded ions are observed, black bar and "Fig 9" indicate the orbit which will be shown expanded in the subequ nt figure); and (g) Dst level (from the Kyoto World Data Center for Gedongetism) for the 5-day period from 11/06/12:00-11/11/12:00, 2004.

Fig re 9. FAST (a) perpendicular and (b) downgoing ion energy spectrograms; (c) low energy ( $0-300 \mathrm{eV})$ and (d) high energy (300-10000 eV) pitch angle spectrograms; and (êtitand (f) O+ ion energy spectrograms from 08:48-09:04 UT on November 8, 2004, takerror ILAT from 63.9-47.3 degrees south, MLT 7.3-8.5 and altitude $~ 3400-3800$ $\mathrm{km} \mathrm{Bla}_{\mathrm{k}}$ vertical line indicates time of data shown in Figure 10. 
Figure 10. Energy flux distribution of all species of ions at (a) 08:59:17 on November 8, 2004 (indicated by the black vertical line in Figure 9), and (b) 02:03:30 on October 31, 2003 (marked by a vertical black line in Figure 5), with the log of the parallel energy on the $\mathrm{x}$-axis and perpendicular energy on the $\mathrm{y}$-axis.

Figure 11. ACE magnetic field measurements of (a) magnitude of $B\left(B_{\text {mag }}\right)$, and (b) North-South component of B $\left(\mathrm{B}_{\mathrm{z}}\right)$; (c) solar wind proton speed, (d) temperature and (e) den fty, (f) FAST ion spectrograms, showing all times when FAST ion data was taken durangers (magenta bars above this panel represent orbits in which banded ions are observed, black bar and "Fig 12" indicate the orbits which will be shown expanded in the subsequent figure); and (g) Dst level (from the Kyoto World Data Center for Geomraghetism) for the 6-day period from November 19-25, 2003.

Fighos. 2. Perpendicular ion spectra from 12 consecutive dayside (MLT 6-12) passes, covpri s the time period 05:23 on November $20-05: 57$ on November 21, 2003; with latilu rom $45-85 \mathrm{deg}$ on the $\mathrm{x}$-axis.

Figure 3. ACE magnetic field measurements of (a) magnitude of $B\left(B_{\text {mag }}\right)$, and (b) North-South component of B $\left(\mathrm{B}_{\mathrm{z}}\right)$; (c) solar wind proton speed, (d) temperature and $(\mathbf{e})$ der rty, (f) FAST ion spectrograms, showing all times when FAST ion data was taken dur store storm (magenta bars above this panel represent orbits in which banded ions are obsenued, black bar and "Fig 14" indicate the orbit which will be shown expanded in the subse unt figure); and (g) Dst level (from the Kyoto World Data Center for Geomagnetism) for the 7-day period from August 25-September 01, 1998.

Figlwe FAST (a) perpendicular and (b) downgoing ion energy spectrograms; (c) low ency (10-300 eV) and (d) high energy (300-10000 eV) pitch angle spectrograms; and (e) $\mathrm{H}+$, (f) $\mathrm{O}+$, and (g) He+ ion energy spectrograms from 05:06-05:11 UT on August 30, 1998 (MLT 2.2-2.3, ILAT 70.4-64.1)

Figre 5. Time (in minutes after 0200 UT on 31 October 2003) vs. 1/E $\mathrm{E}^{1 / 2}$ plots for a subets the LANL 02A ion band observations (thick lines) shown in Figure 7, with linear fits to each band shown underlying the observations, for (a) north- and (b) southloo ing directions.

Fyirt 16. The slopes of the bands from the linear fits shown in Figure 16, as well as thorved with another LANL satellite (97A), (along with the calculated errors in the fits) or comparison with the slopes expected for an ionospheric source $(S=1 / 2,21 / 2$, $51 / 2, \ldots)$ or an equatorial source $(S=1,21,31, \ldots)$, where 1 is the length of the field line 
through the geosynchronous location. The assumed species are $\mathrm{H}^{+}$(top), $\mathrm{He}^{+}$(middle) and $\mathrm{O}^{+}$(bottom).

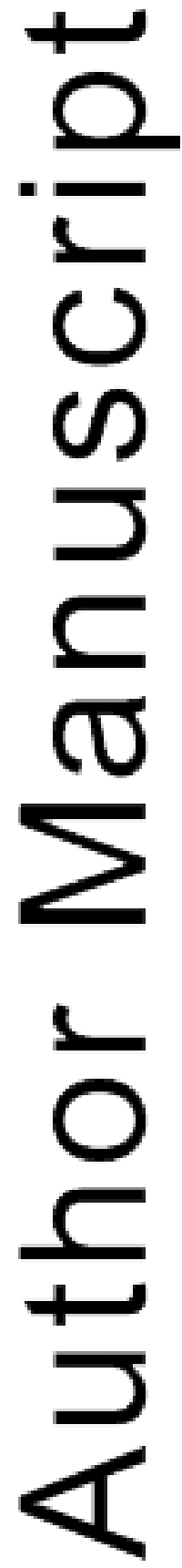

This article is protected by copyright. All rights reserved. 
Table 1: List of large geomagnetic storms investigated. Date, minimum Dst, and presence of banded ions and banded waves are indicated. " $P$ " indicates possible, but not clear, presence of banded waves, green shading represents FAST wave data, yellow shading DEMETER data and "N/A" indicates no wave data available on FAST or DEMETER.

\begin{tabular}{|c|c|c|c|}
\hline Date & Min Dst & Banded Ions & Banded Waves \\
\hline 3-05/07/98 & -205 & $\mathbf{Y}$ & $\mathbf{Y}$ \\
\hline $08 / 31 / 98$ & -155 & $\mathbf{Y}$ & $\mathbf{Y}$ \\
\hline $25-09 / 26 / 98$ & -207 & $\mathbf{Y}$ & $\mathbf{Y}$ \\
\hline $22-09 / 24 / 99$ & -173 & $\mathbf{Y}$ & $\mathbf{Y}$ \\
\hline $22-10 / 25 / 99$ & -237 & $\mathbf{Y}$ & $\mathbf{Y}$ \\
\hline $6-04 / 08 / 00$ & -288 & $\mathbf{Y}$ & $\mathbf{Y}$ \\
\hline $15-07 / 17 / 00$ & -301 & $\mathbf{Y}$ & $\mathbf{P}$ \\
\hline $12-08 / 14 / 00$ & -235 & $\mathbf{Y}$ & $\mathbf{P}$ \\
\hline $7-09 / 19 / 00$ & -201 & $\mathbf{Y}$ & $\mathbf{Y}$ \\
\hline $04-10 / 06 / 00$ & -182 & $\mathbf{Y}$ & $\mathbf{Y}$ \\
\hline $6-11 / 07 / 00$ & -159 & $\mathbf{Y}$ & $\mathbf{Y}$ \\
\hline 3/31-04/01/01 & -387 & $\mathbf{Y}$ & N/A \\
\hline $11-04 / 12 / 01$ & -271 & $\mathbf{Y}$ & N/A \\
\hline $10 / 21-10 / 25 / 01$ & -187 & $\mathbf{Y}$ & N/A \\
\hline $27-10 / 31 / 01$ & -157 & $\mathbf{Y}$ & $\mathbf{N} / \mathbf{A}$ \\
\hline $6-11 / 07 / 01$ & -292 & $\mathbf{Y}$ & N/A \\
\hline 7-04/19/02 & -127 & $\mathbf{Y}$ & N/A \\
\hline $9-04 / 21 / 02$ & -149 & $\mathbf{Y}$ & N/A \\
\hline $9-10 / 30 / 03$ & -353 & $\mathbf{Y}$ & N/A \\
\hline $10 / 30-10 / 31 / 03$ & -383 & $\mathbf{Y}$ & N/A \\
\hline $11 / 20-11 / 21 / 03$ & -422 & $\mathbf{Y}$ & $\mathbf{N} / \mathbf{A}$ \\
\hline $26-07 / 30 / 04$ & -197 & $\mathbf{Y}$ & $\mathbf{Y}$ \\
\hline $30-08 / 31 / 04$ & -126 & $\mathbf{Y}$ & $\mathbf{Y}$ \\
\hline $7-11 / 08 / 04$ & -373 & $\mathbf{Y}$ & $\mathbf{Y}$ \\
\hline $11 / 09-11 / 10 / 04$ & -289 & $\mathbf{Y}$ & $\mathbf{Y}$ \\
\hline$/ 18-01 / 20 / 05$ & -121 & $\mathbf{Y}$ & $\mathbf{P}$ \\
\hline $21-01 / 23 / 05$ & -105 & $\mathbf{Y}$ & $\mathbf{Y}$ \\
\hline $08-05 / 10 / 05$ & -127 & $\mathbf{Y}$ & $\mathbf{P}$ \\
\hline $15-05 / 19 / 05$ & -263 & $\mathbf{Y}$ & $\mathbf{Y}$ \\
\hline $20-05 / 22 / 05$ & -103 & $\mathbf{Y}$ & $\mathbf{Y}$ \\
\hline $30-05 / 31 / 05$ & -138 & $\mathbf{Y}$ & $\mathbf{Y}$ \\
\hline $2-06 / 13 / 05$ & -106 & $\mathbf{Y}$ & $\mathbf{Y}$ \\
\hline
\end{tabular}


08/24-08/26/05

08/31-09/03/05

09/11-09/12/05

$-147$

04/14-04/15/06

$-111$

$12 / 15-12 / 16 / 06$

$-146$

$$
\mathbf{Y}
$$

Y
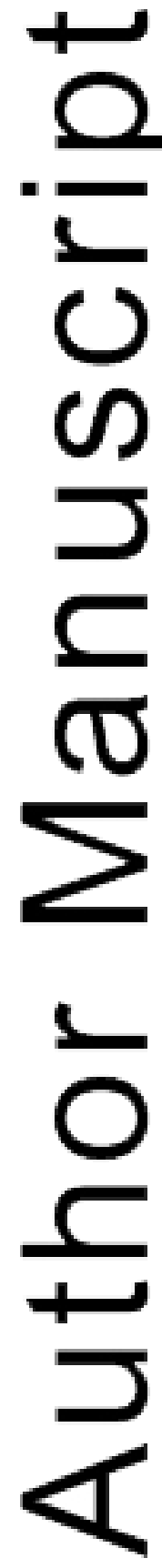

This article is protected by copyright. All rights reserved. 


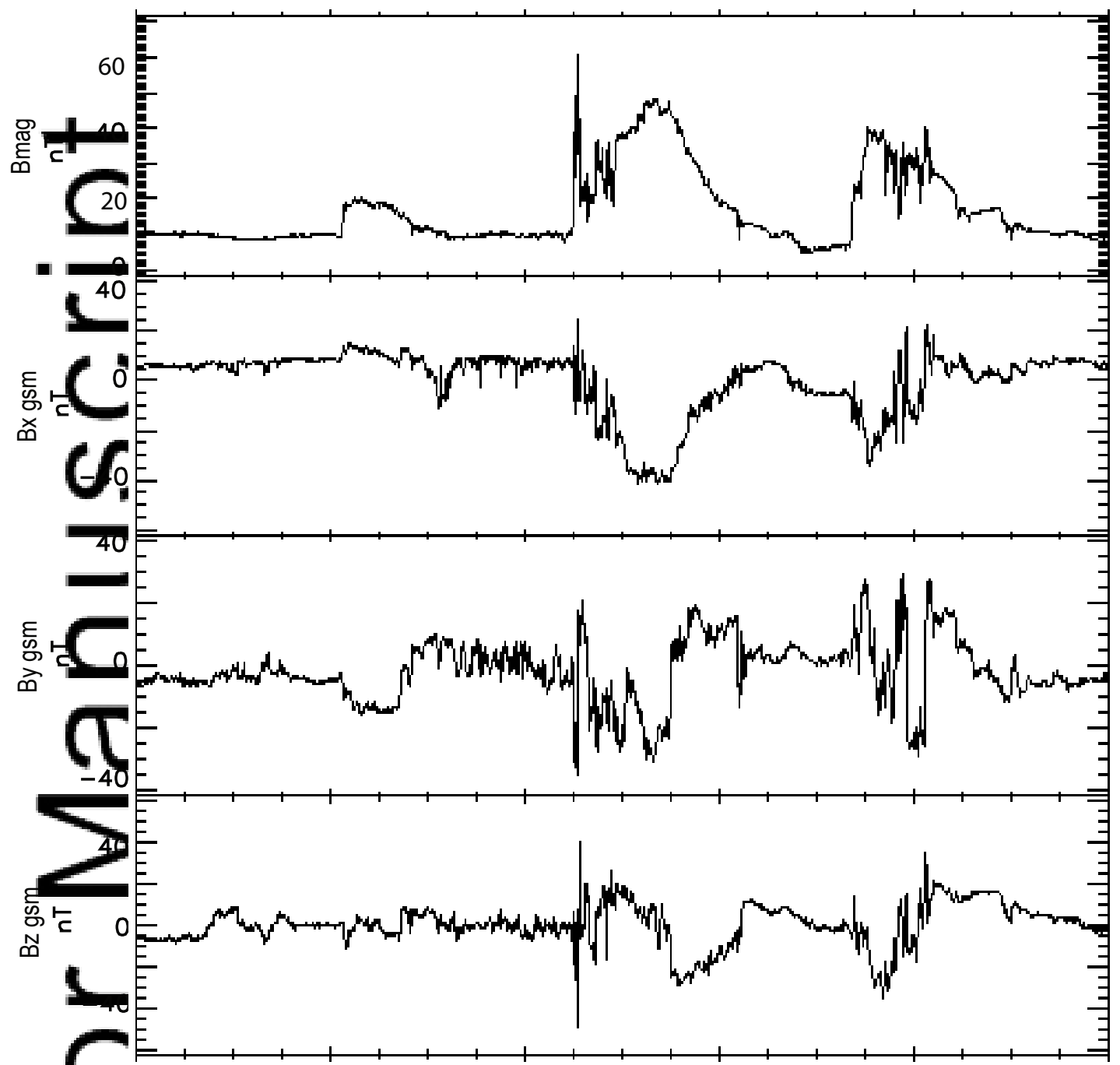

(a)

(b)

(c)

(d)

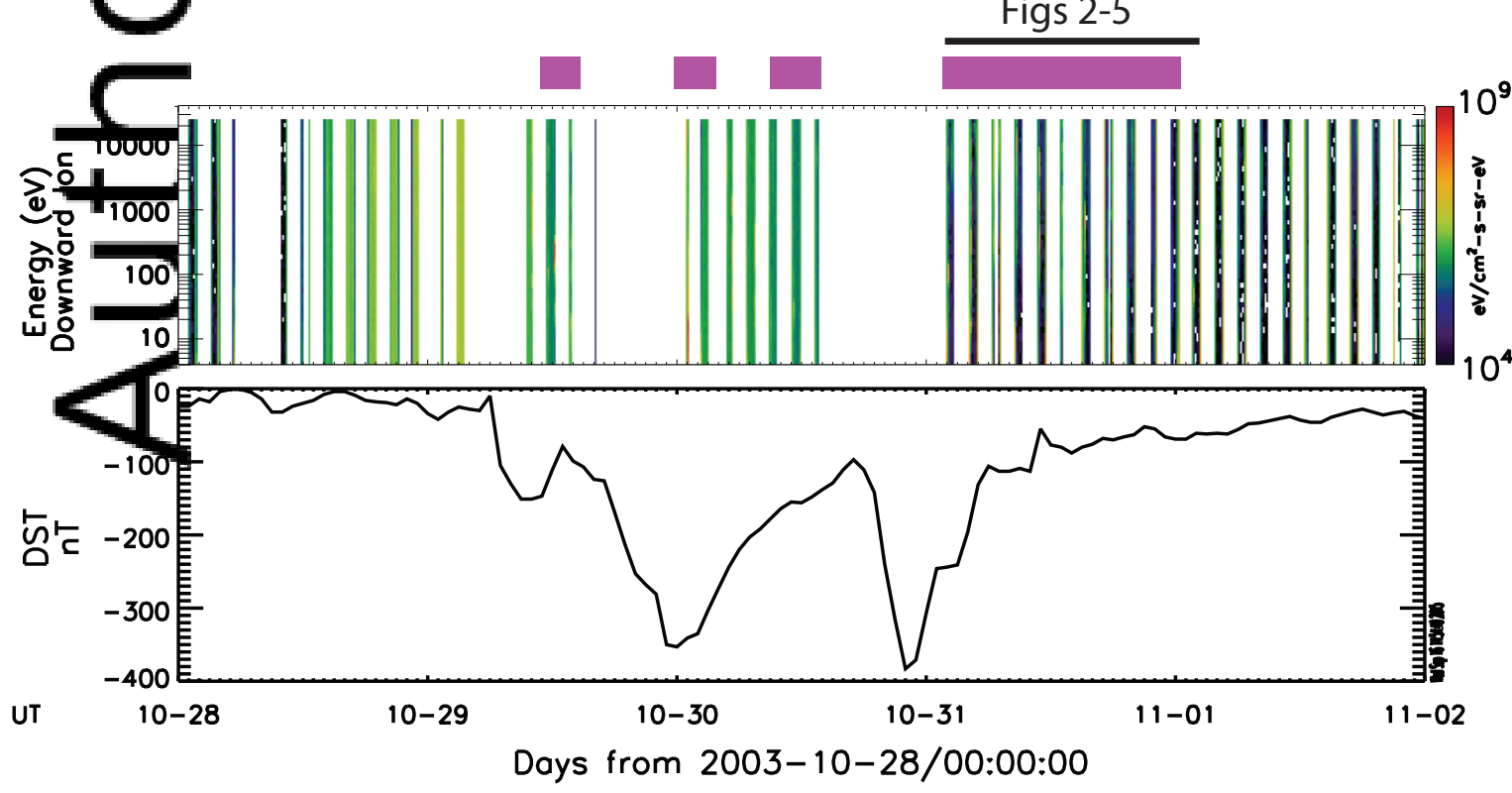

(e)

(f)

This article is protected by copyright. All rights reserved. 


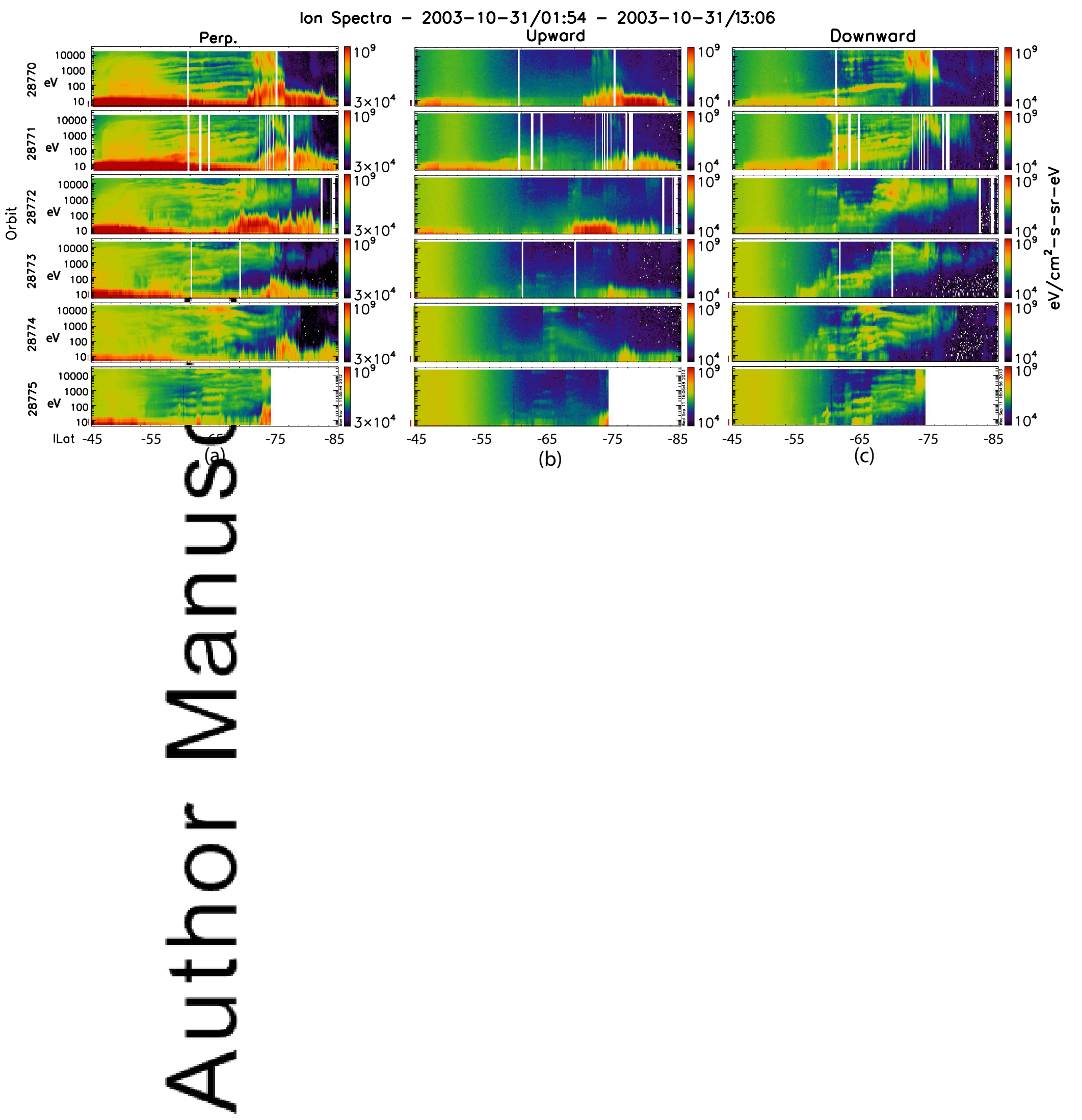

This article is protected by copyright. All rights reserved. 
Perp. Ion Spectra - 2003-10-31/14:55 - 2003-11-01/02:30
Downword Electron Spectro - 2003-10-31/14:55 - 2003-11-01/02:30
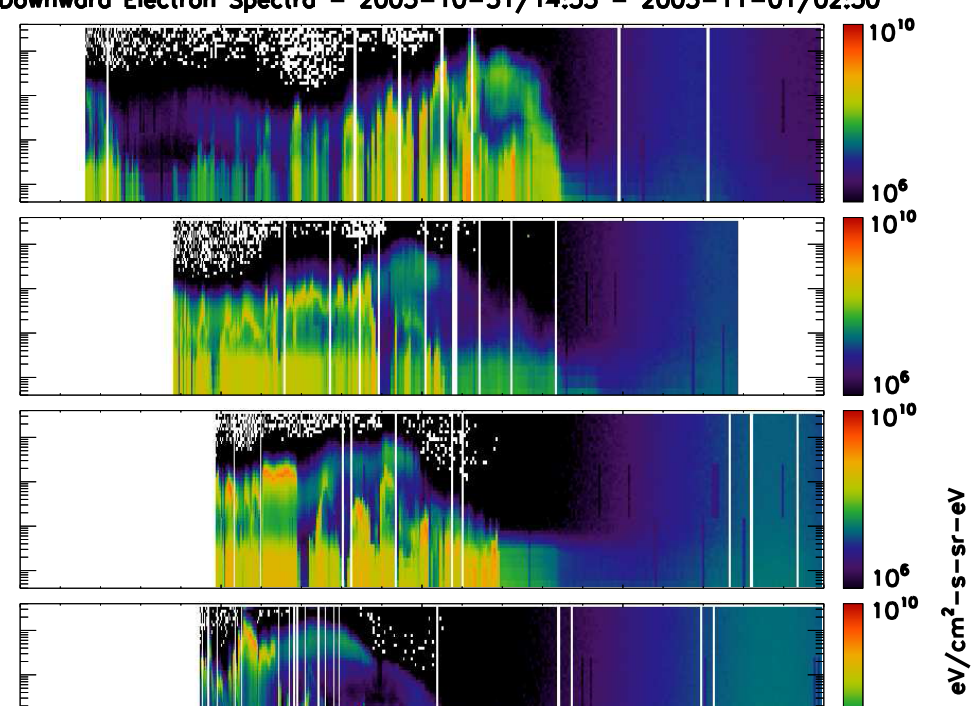

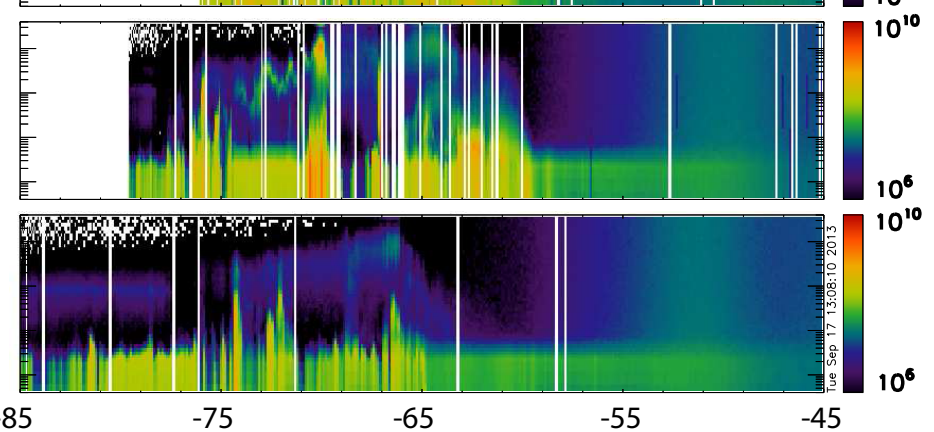

(a)

(b)

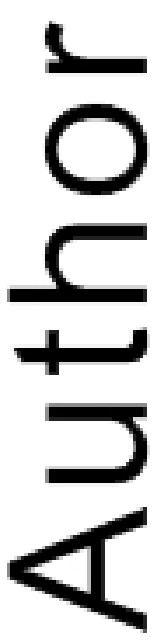

This article is protected by copyright. All rights reserved. 


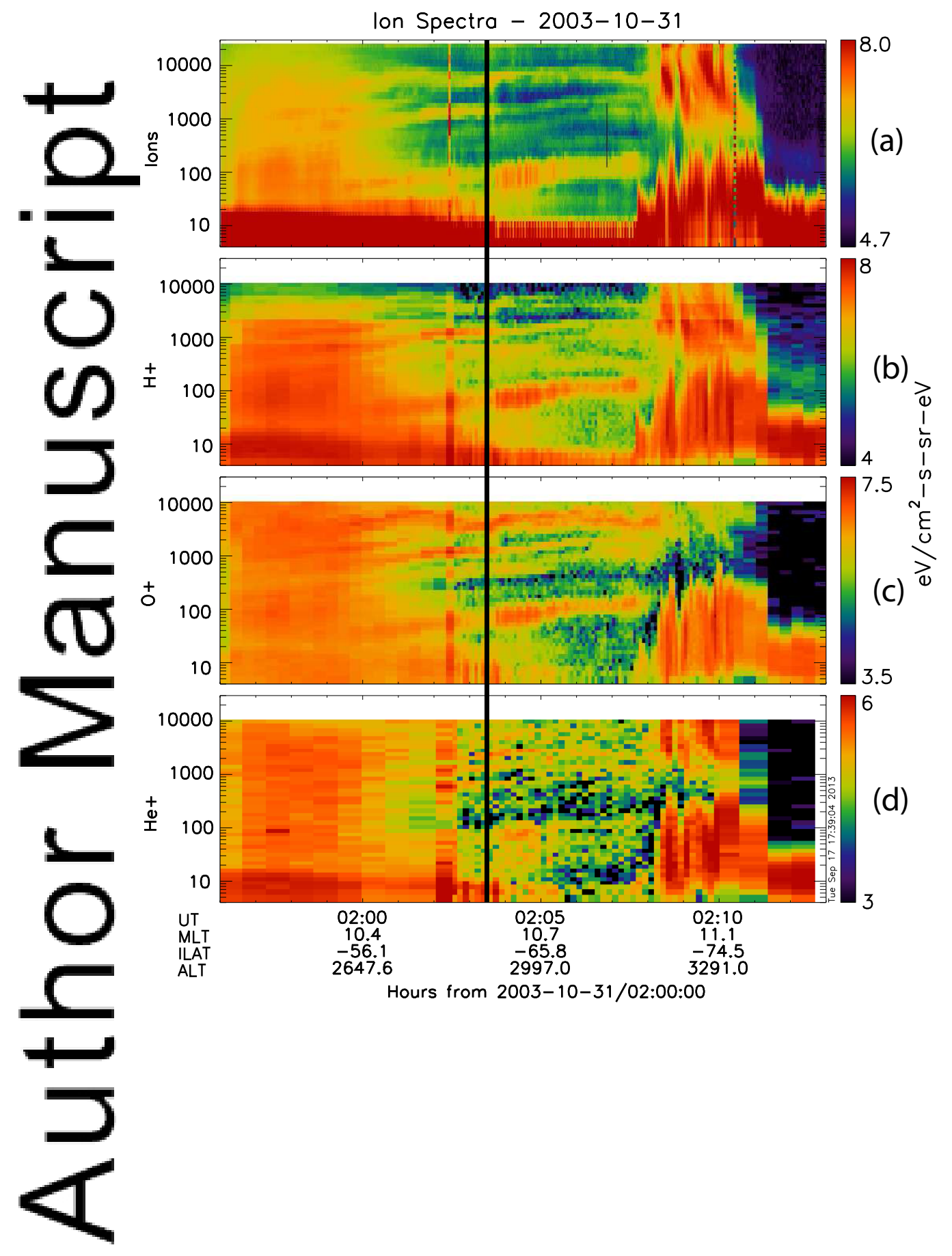

This article is protected by copyright. All rights reserved. 
FAST lesa Survey Eflux

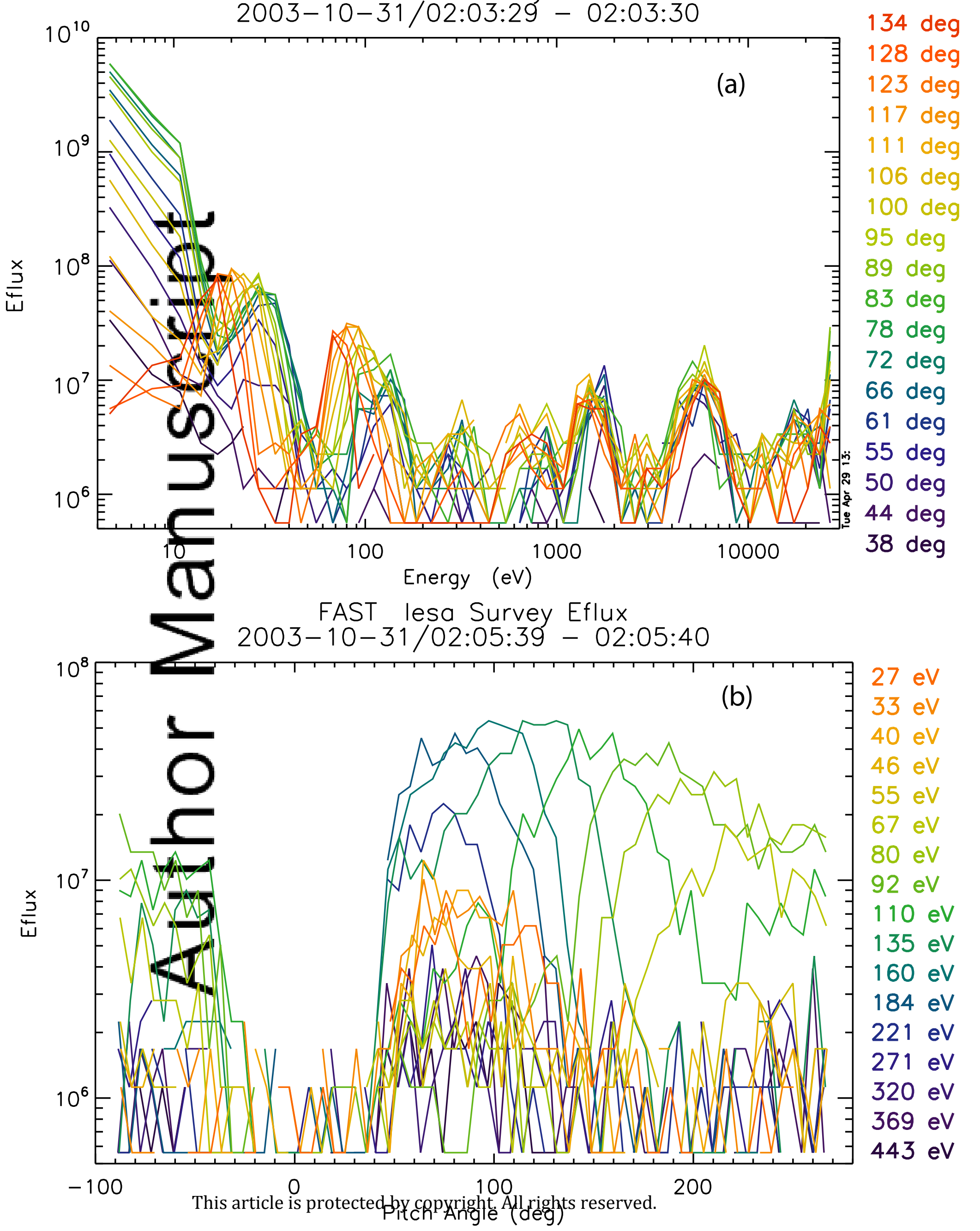




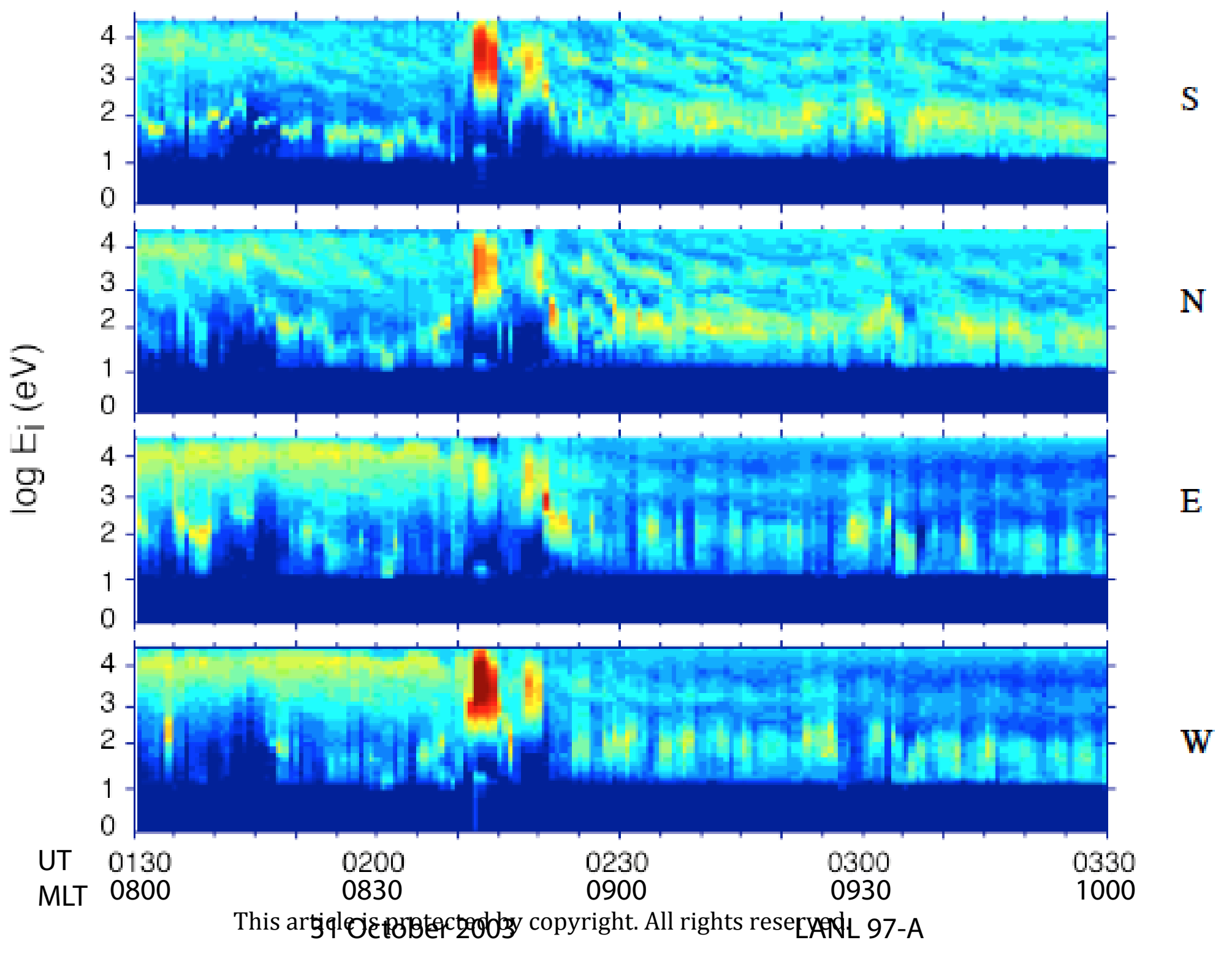


FAST Orbits 32936 to 32992 Ion

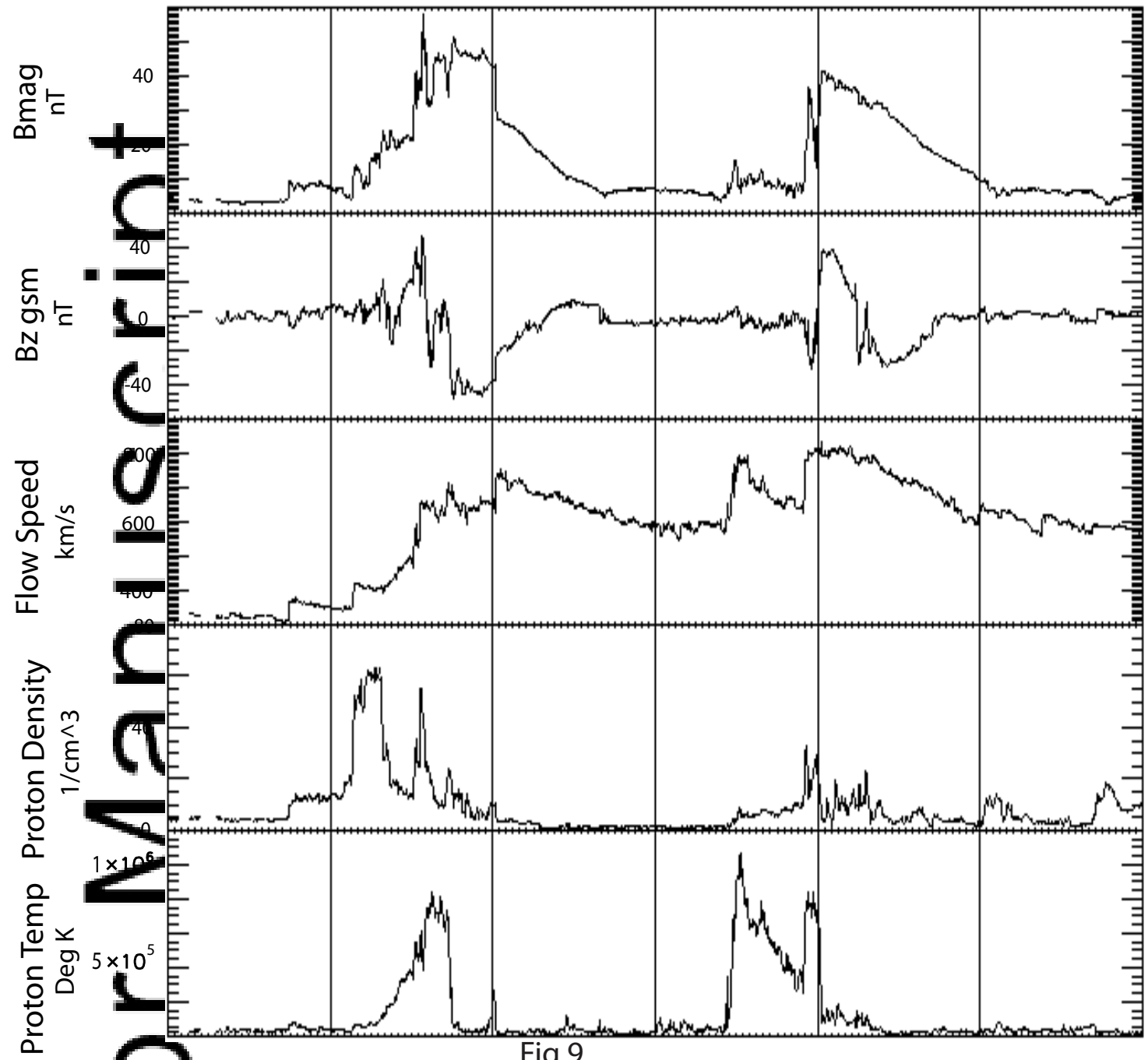

(a)

(b)

(c)

(d)

(e)

Fig 9
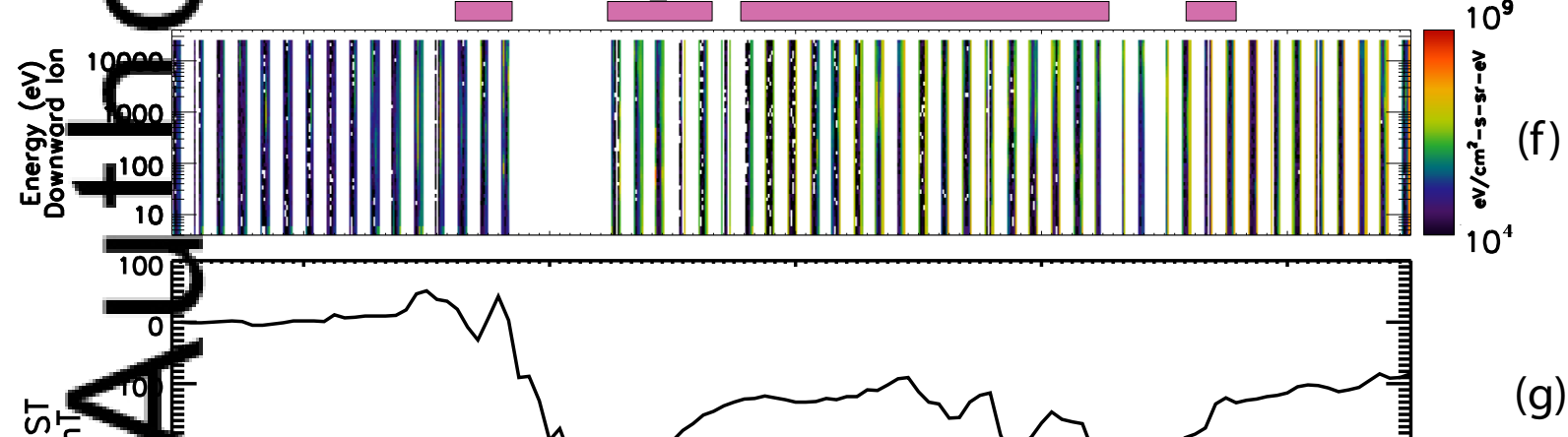

UT
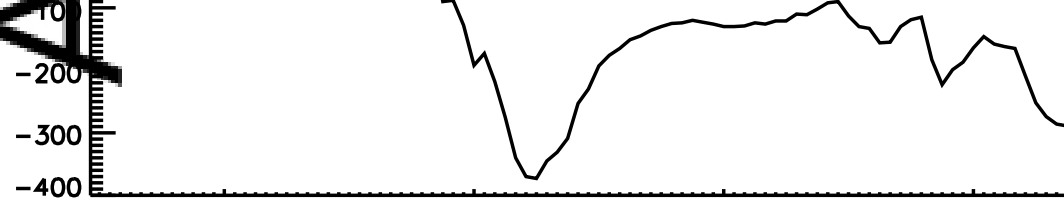

(g) 


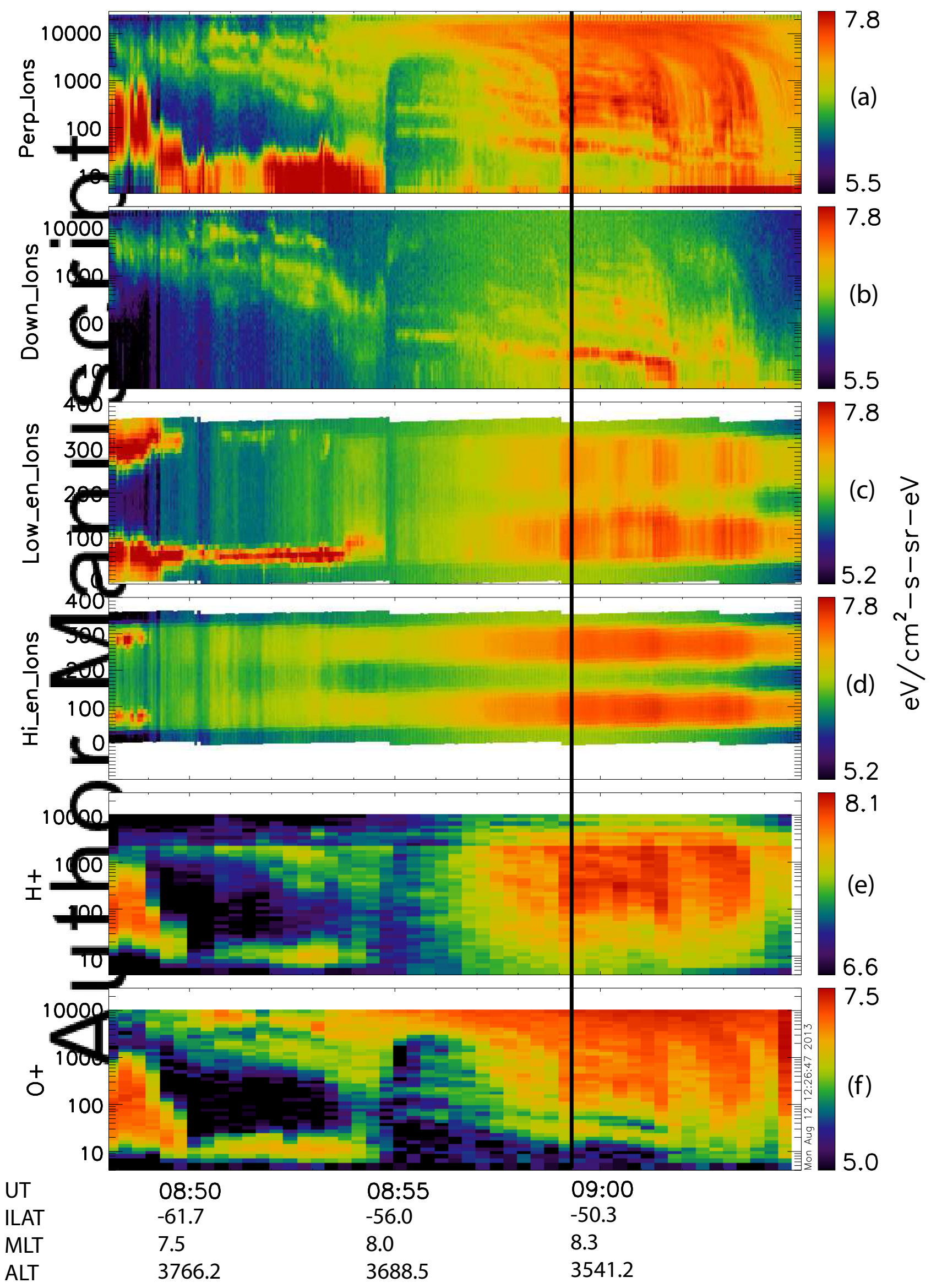

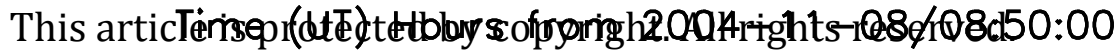




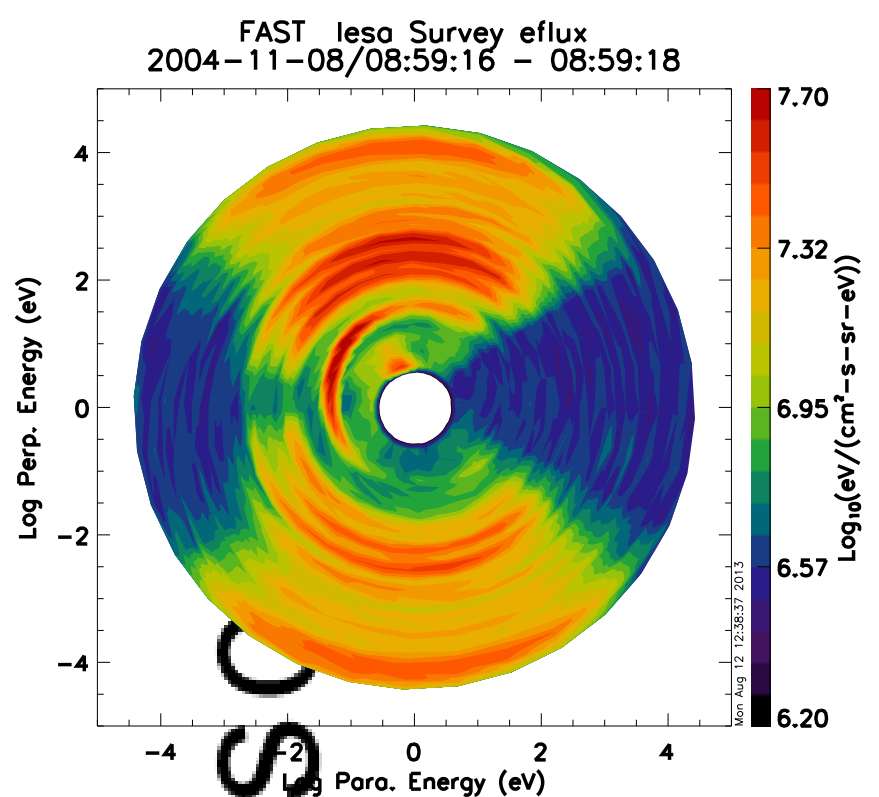

(a)

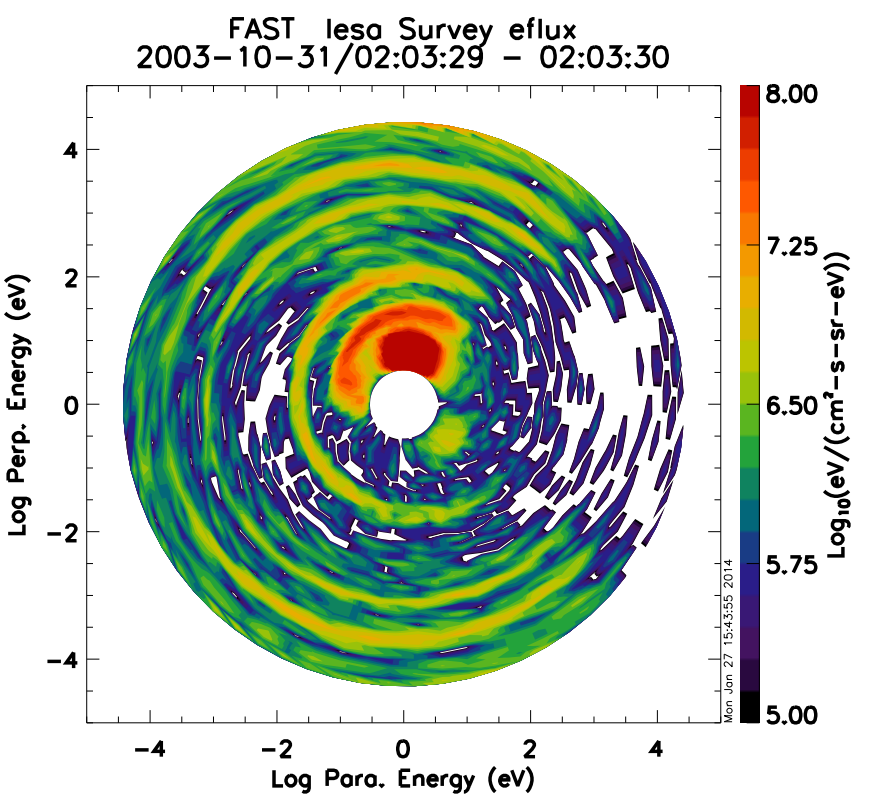

(b)

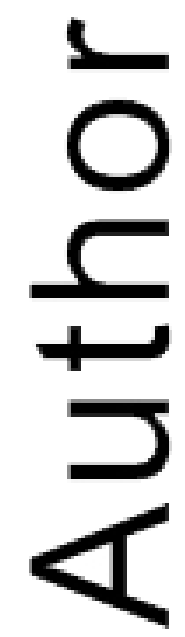

This article is protected by copyright. All rights reserved. 


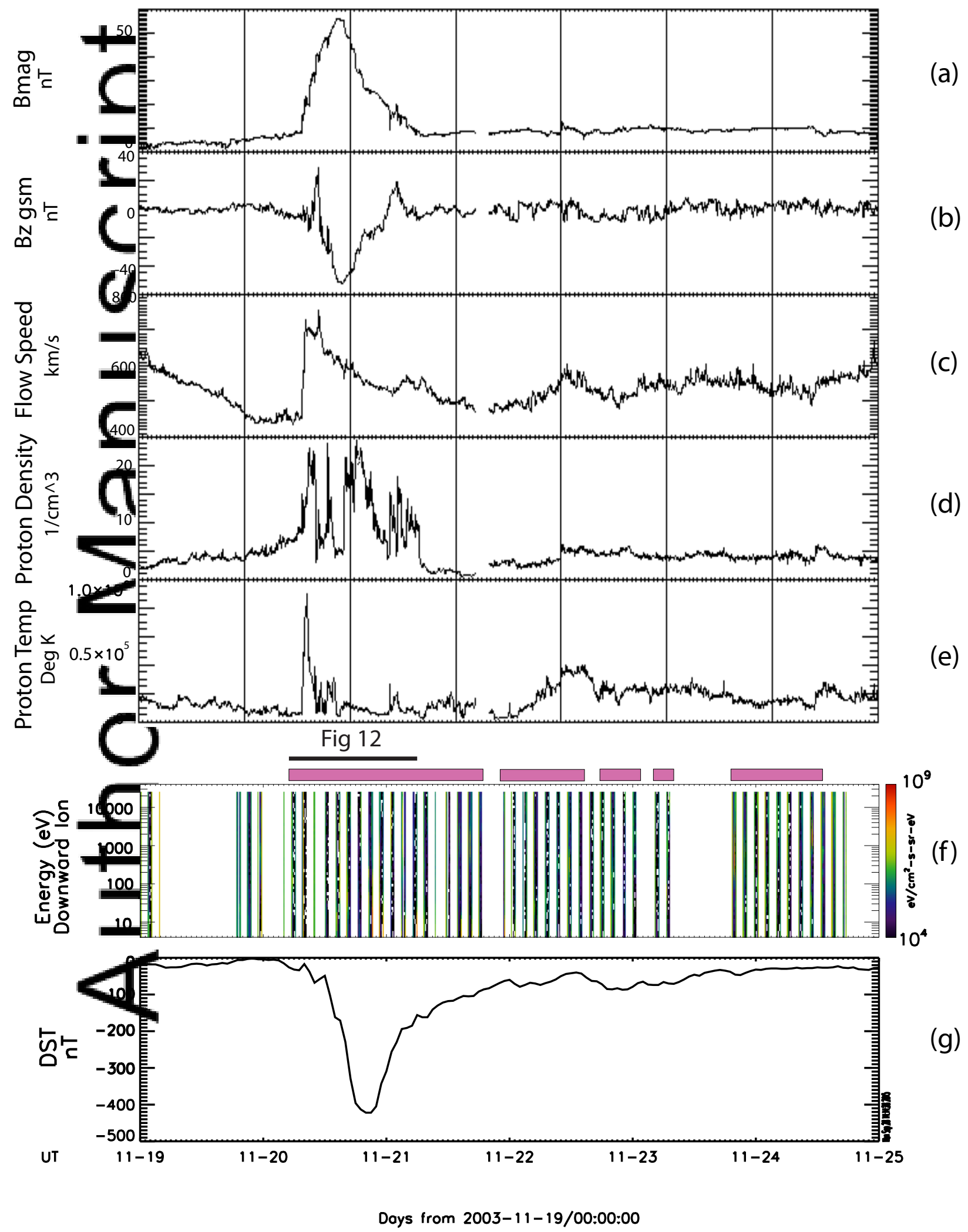

This article is protected by copyright. All rights reserved. 

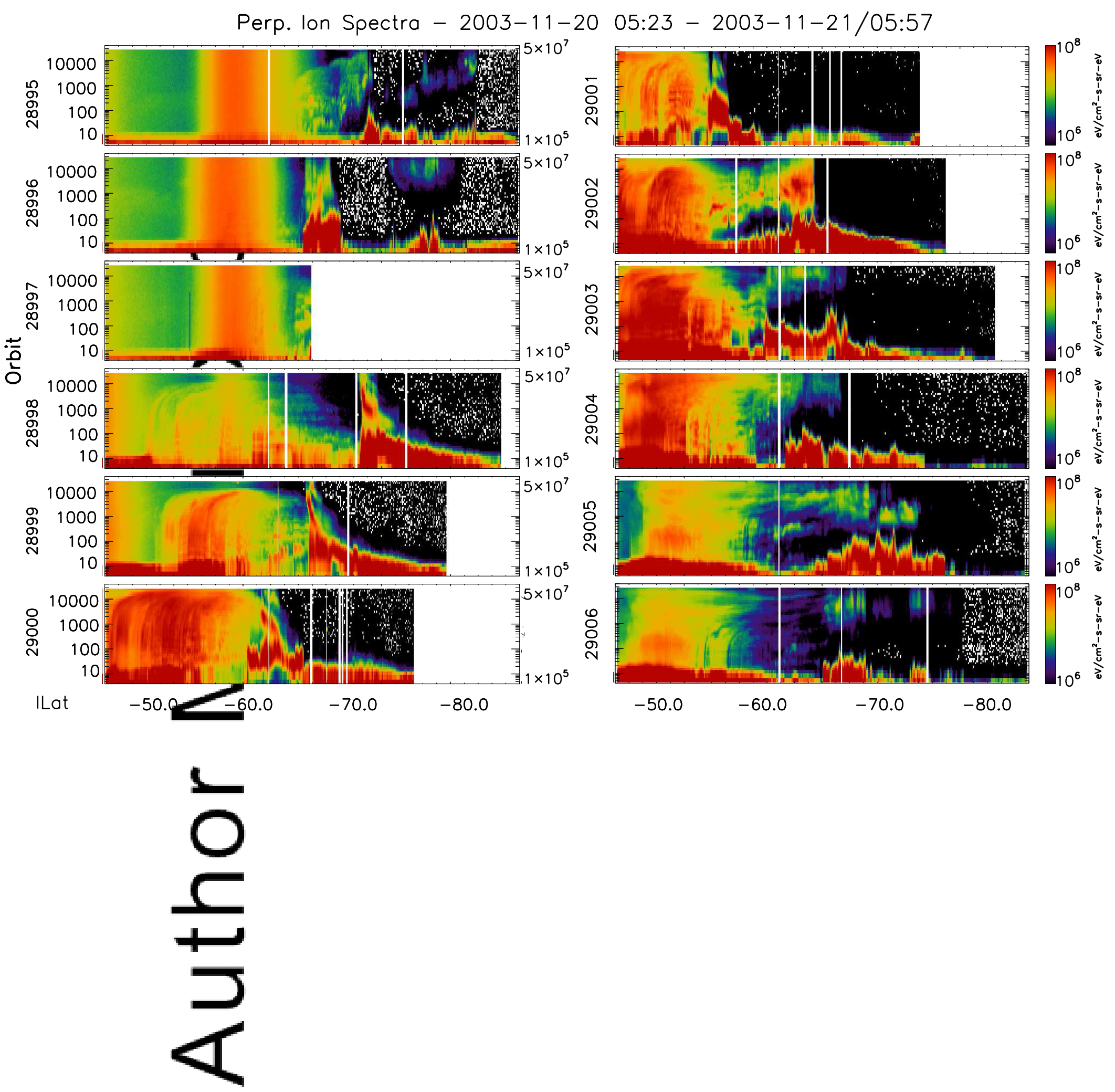

This article is protected by copyright. All rights reserved. 


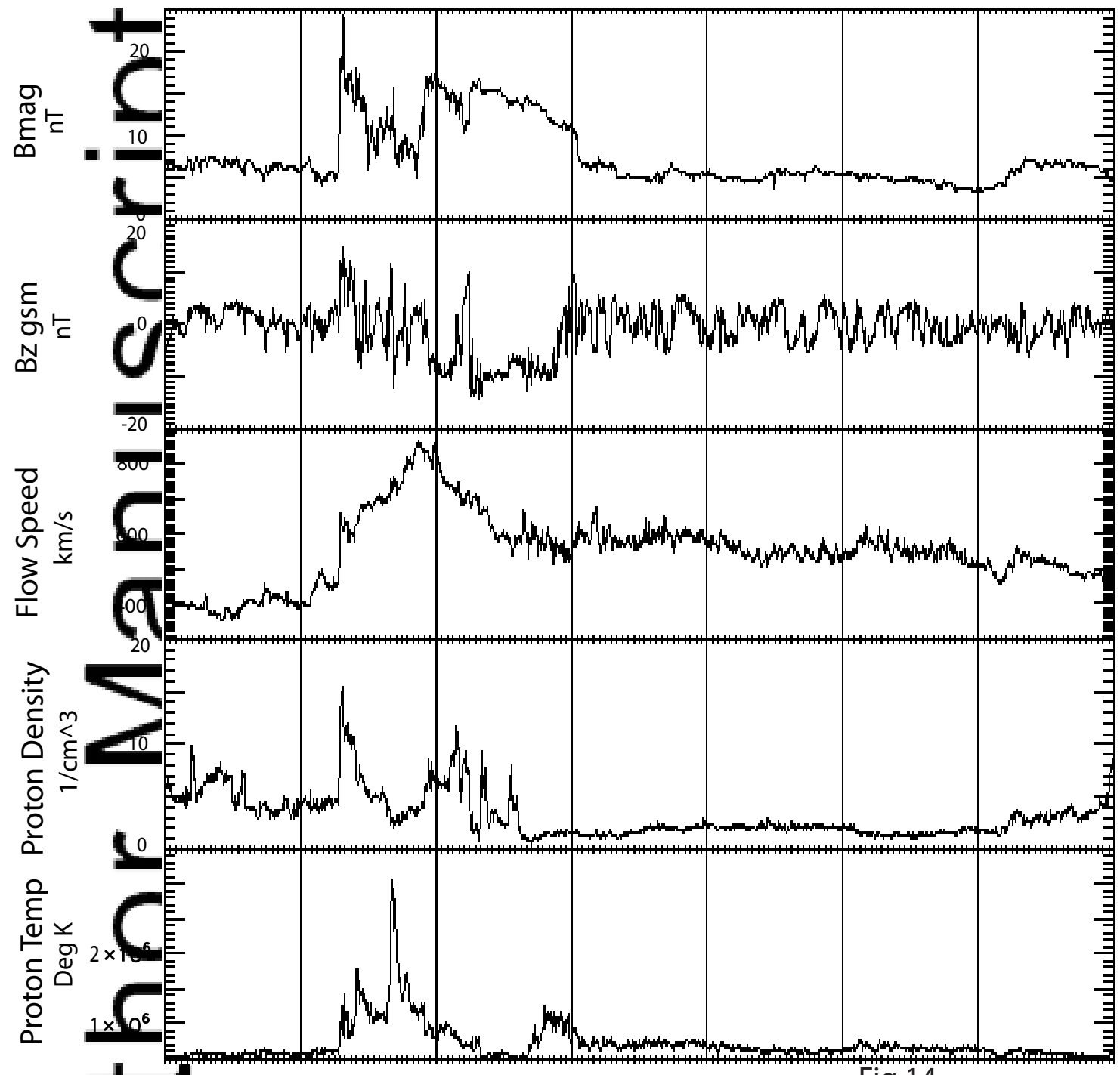

(a)

(b)

(c)

(d)

(e)

Fig 14

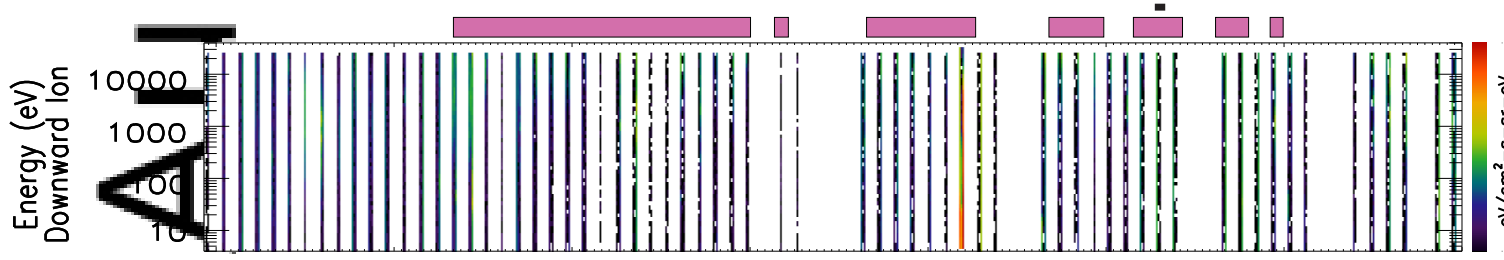

$10^{9}$

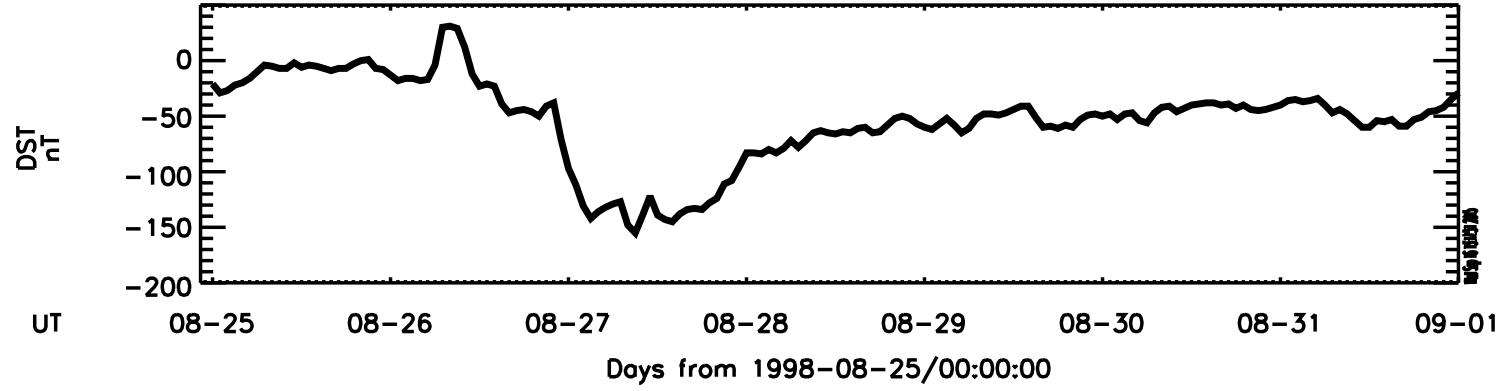

(g)

This article is protected by copyright. All rights reserved. 


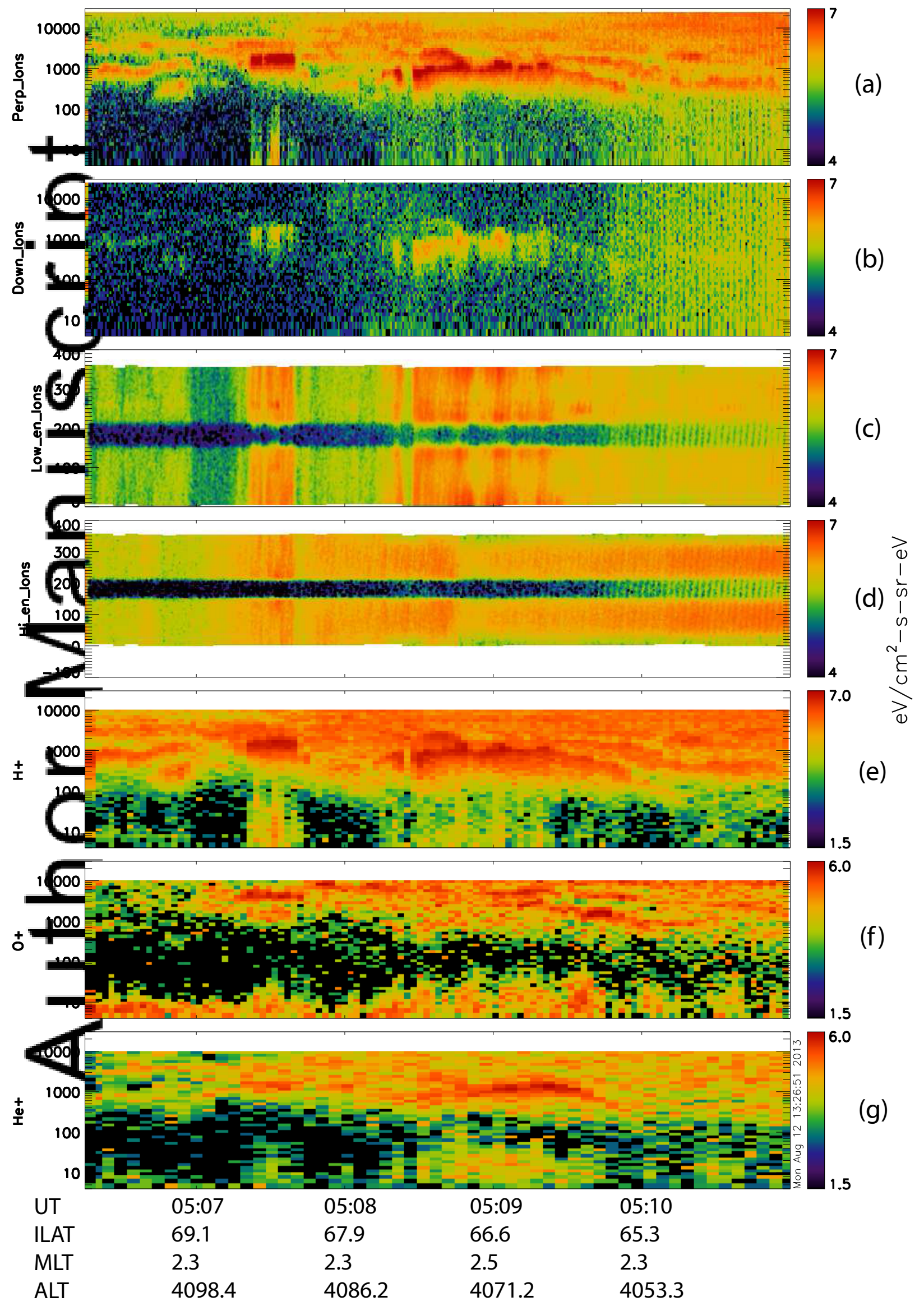

Time (UT) Hours from 1998-08-30/05:07:00

This article is protected by copyright. All rights reserved. 
LANL-02A 31 Oct 2003 02-03 UT

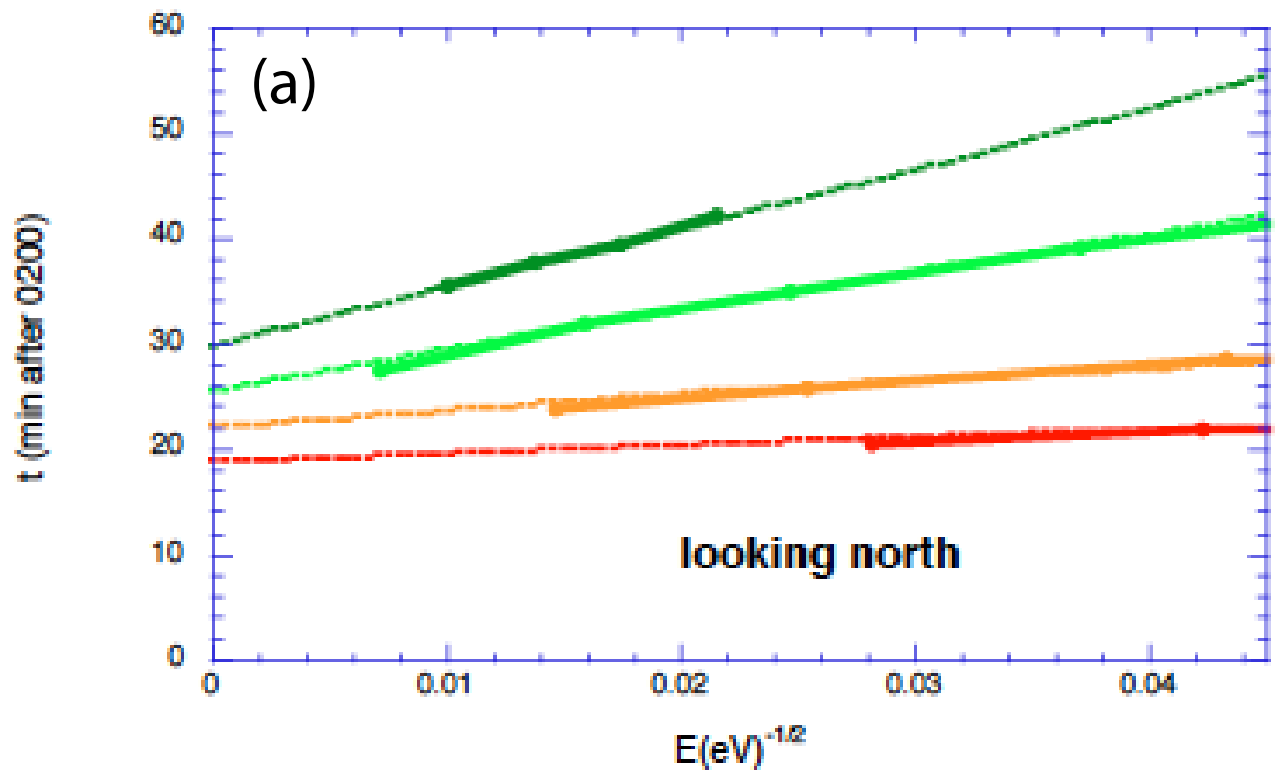

LANL-02A 31 Oct 2003 02-03 UT

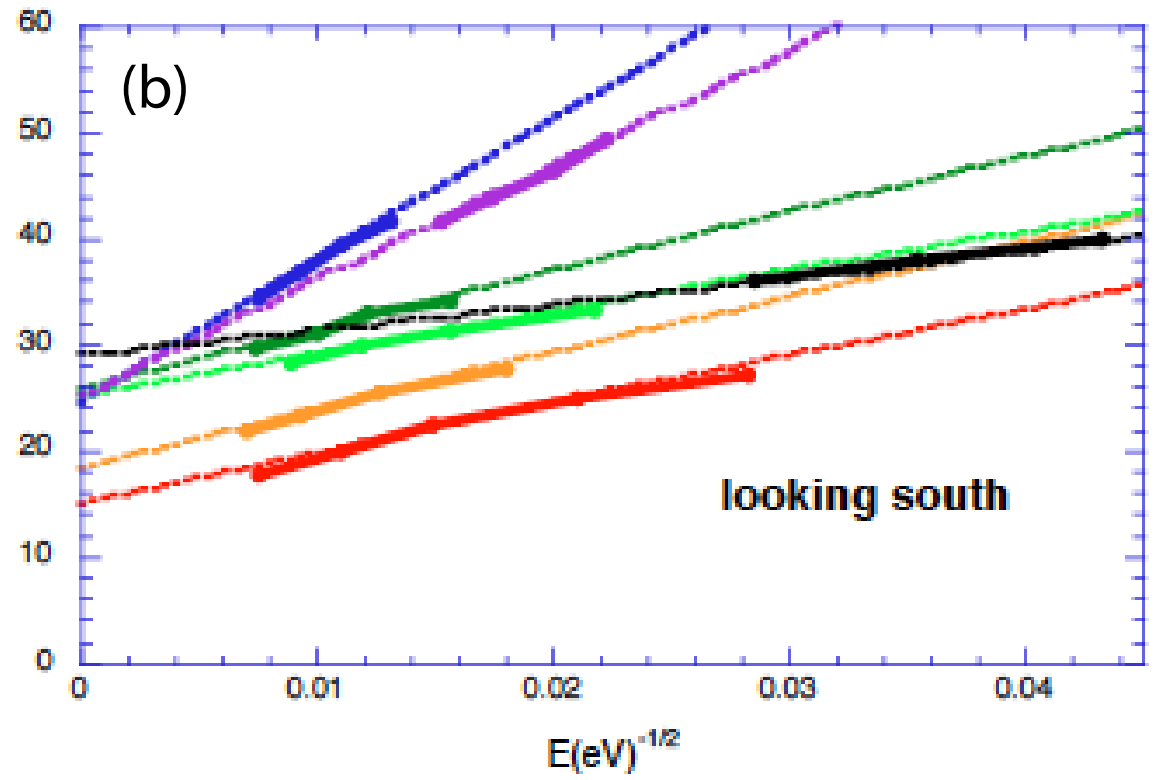

This article is protected by copyright. All rights reserved. 


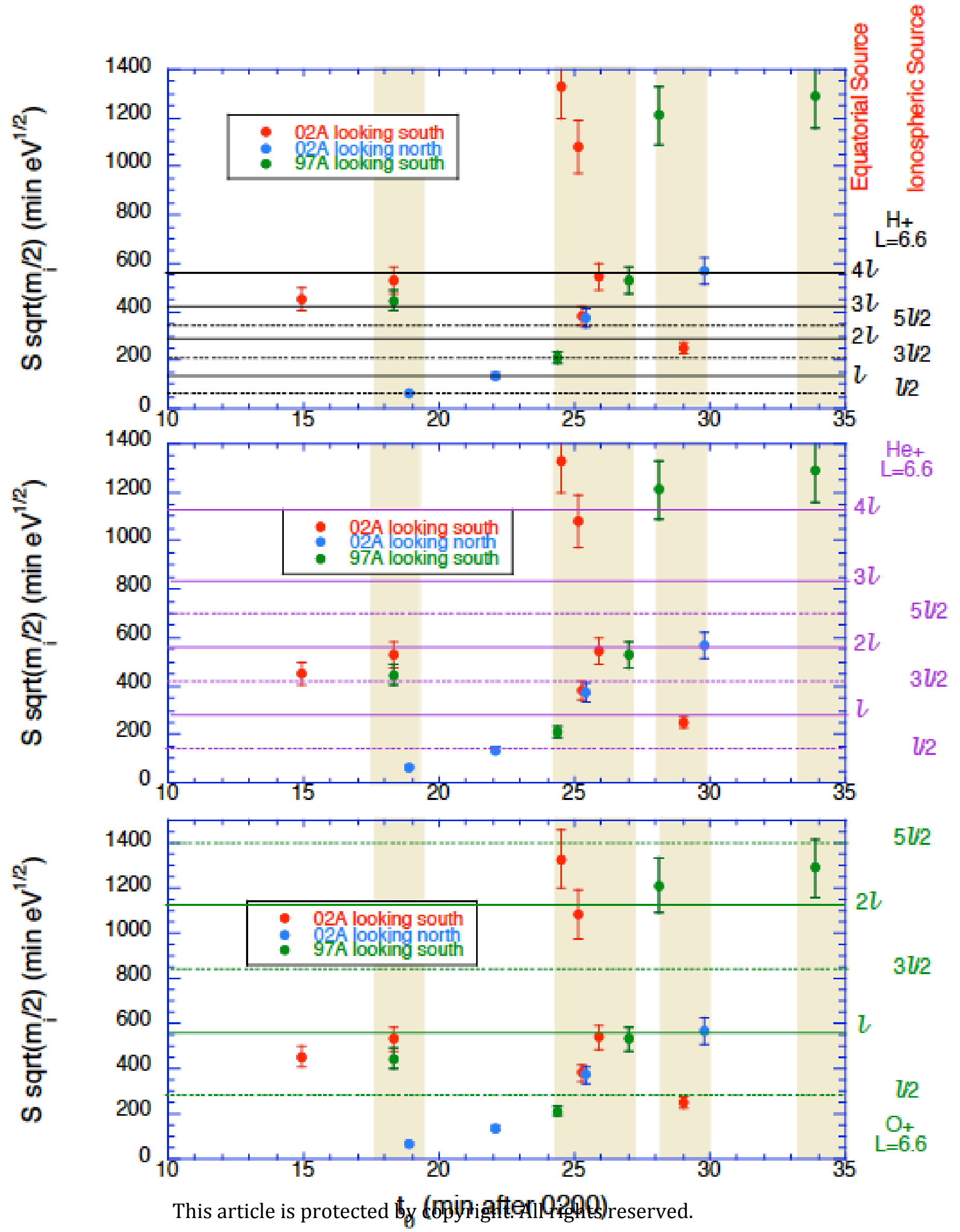

